\title{
Present and Future Perspectives on Therapeutic Options for Carbapenemase-Producing Enterobacterales Infections
}

\author{
Corneliu Ovidiu Vrancianu ${ }^{1,2}{ }^{\oplus}$, Elena Georgiana Dobre ${ }^{1}\left(\mathbb{D}\right.$, Irina Gheorghe ${ }^{1,2, *}$, Ilda Barbu ${ }^{1,2}$, \\ Roxana Elena Cristian ${ }^{3}(1)$ and Mariana Carmen Chifiriuc ${ }^{1,2}$ \\ 1 Microbiology Immunology Department, Faculty of Biology, University of Bucharest, \\ 050095 Bucharest, Romania; ovidiu.vrancianu@yahoo.com (C.O.V.); dobregeorgiana_95@yahoo.com (E.G.D.); \\ ilda.czobor@yahoo.com (I.B.); carmen.chifiriuc@bio.unibuc.ro (M.C.C.) \\ 2 The Research Institute of the University of Bucharest, 050095 Bucharest, Romania \\ 3 Department of Biochemistry and Molecular Biology, Faculty of Biology, University of Bucharest, \\ 050095 Bucharest, Romania; roxana.cristian95@yahoo.com \\ * Correspondence: iryna_84@yahoo.com
}

check for updates

Citation: Vrancianu, C.O.; Dobre, E.G.; Gheorghe, I.; Barbu, I.; Cristian, R.E.; Chifiriuc, M.C. Present and Future Perspectives on Therapeutic Options for CarbapenemaseProducing Enterobacterales Infections. Microorganisms 2021, 9, 730 .

https://doi.org/10.3390/

microorganisms 9040730

Academic Editor: Jorge Blanco

Received: 8 March 2021

Accepted: 30 March 2021

Published: 31 March 2021

Publisher's Note: MDPI stays neutral with regard to jurisdictional claims in published maps and institutional affiliations.

Copyright: (C) 2021 by the authors. Licensee MDPI, Basel, Switzerland. This article is an open access article distributed under the terms and conditions of the Creative Commons Attribution (CC BY) license (https:/ / creativecommons.org/licenses/by/ $4.0 /)$.

\begin{abstract}
Carbapenem-resistant Enterobacterales (CRE) are included in the list of the most threatening antibiotic resistance microorganisms, being responsible for often insurmountable therapeutic issues, especially in hospitalized patients and immunocompromised individuals and patients in intensive care units. The enzymatic resistance to carbapenems is encoded by different $\beta$-lactamases belonging to A, B or D Ambler class. Besides compromising the activity of last-resort antibiotics, CRE have spread from the clinical to the environmental sectors, in all geographic regions. The purpose of this review is to present present and future perspectives on CRE-associated infections treatment.
\end{abstract}

Keywords: Carbapenem-resistant Enterobacterales (CRE); multi-drug resistance; novel antibiotics

\section{Introduction}

In 2017, the World Health Organization (WHO) published a list of resistant bacteria against which there is an urgent need to develop new antibiotics [1]. Critical priority bacteria included carbapenem-resistant Enterobacterales (CRE). These bacteria are among the most common pathogens associated with severe infections, such as sepsis, pneumonia, urinary tract, and intra-abdominal infections, having, which along with the current COVID-19 pandemic are having a major impact, both clinically and economically [2]. Initially, Enterobacteriaceae posed a threat to public health because of their ability to resist the action of $\beta$-lactam antibiotics (BLAs) by producing broad-spectrum $\beta$-lactamases. At first, these enzymes inactivated penicillins, but later, due to the introduction of new antibiotics for the treatment of infections, their spectrum expanded. This situation has led to the intensive use of carbapenems as first-line drugs, leading to CRE's emergence over time [3]. There are three main mechanisms of CRE resistance, i.e., enzyme production (extendedspectrum beta-lactamases (ESBLs), metallo-beta-lactamases (MBLs) and other categories of carbapenemases), efflux pumps, and porin mutations [4,5]. Depending on the type of resistance mechanism, CREs are divided into carbapenemase-producing CREs (CP-CREs) and non-CP-CREs. CP-CRE can produce a large variety of carbapenemases which can be divided into three groups according to the Ambler classification: class A, class B and class D B-lactamases [4]. Regarding the fourth class, the clinical relevance of C Ambler class enzymes remains to be solved [5]. CRE can accumulate many carbapenem resistance mechanisms, such as porin loss, efflux pump overexpression and changes in penicillin-binding proteins [6,7] (Figure 1). While carbapenemases specifically target carbapenems and other categories of BLA, efflux pumps and porin changes are associated with the presence of multidrug resistance (MDR) [8], blocking the penetration of different antibiotics into the bacterial cell. 


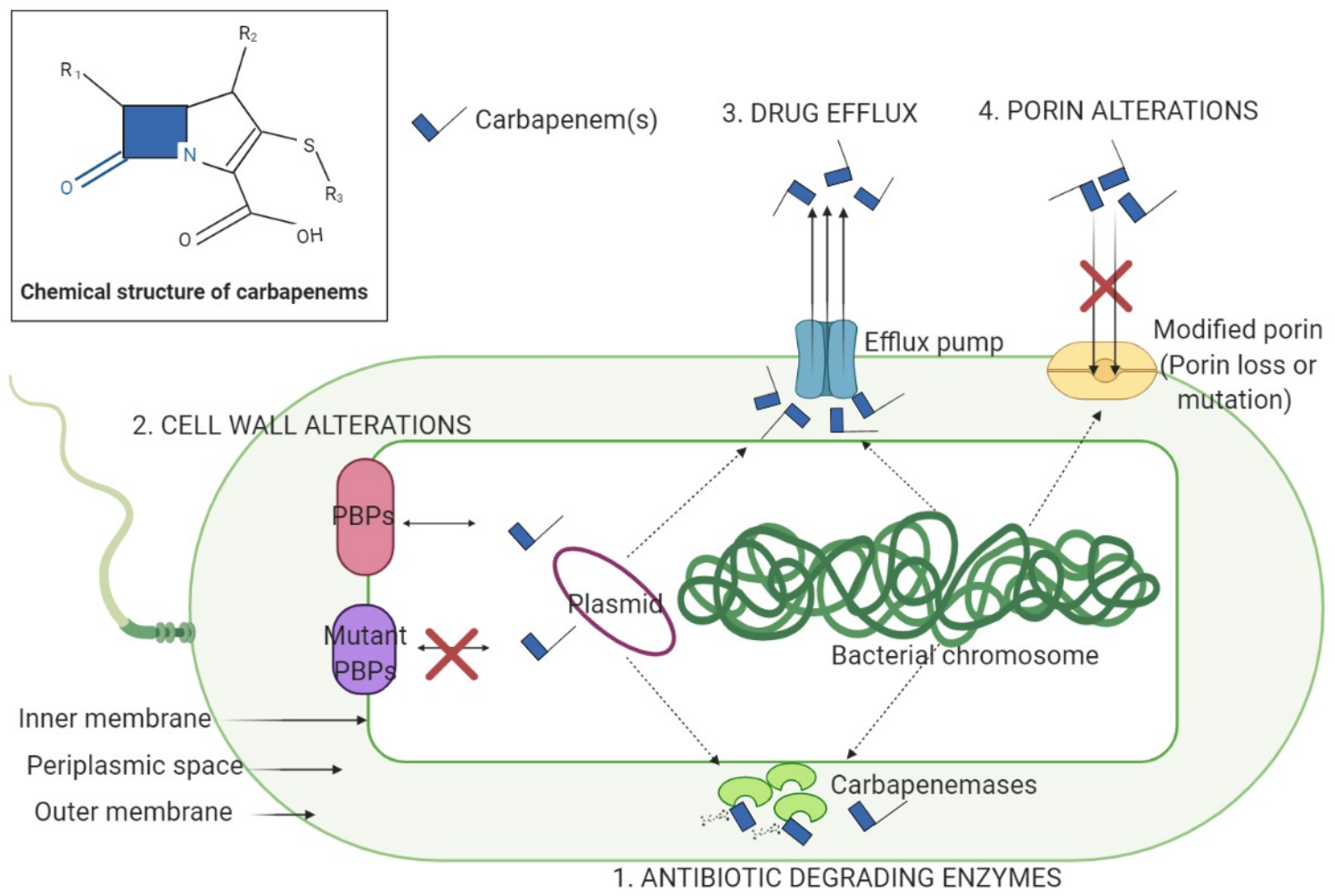

Figure 1. Major resistance mechanisms associated with carbapenem-resistant Enterobacterales (CRE) infections.

In response to the CRE threat, efforts have been made to reduce the spread and prevent the development of resistance, reducing nosocomial infections associated with CRE by up to $60 \%$ by the end of 2020 [9]. The Infectious Diseases Society of America has launched the " $10 \times 20$ " campaign to develop 10 new antibiotics by the end of 2020, with two such antibiotics (e.g., telavancin and ceftaroline fosamil) already receiving FDA approval [10]. In this review, old and current antibiotics, and future promising perspectives that are currently under investigation for winning the war against the emerging CREs are briefly discussed.

\section{CRE Permeability and the Impact of Porin Deletions and Efflux Pumps}

The efficiency of antibacterial agents is related to their capacity to reach inhibitory concentrations in the vicinity of their target, an aspect that is particularly challenging in Gram-negative bacteria, due to their complex envelope structure [11]. The Gram-negative envelope consists of an inner membrane (IM), which is a symmetric phospholipid bilayer, a thin peptidoglycan (PG) layer, and an outer membrane (OM). The OM acts as a barrier to hydrophobic and hydrophilic compounds, including nutrients, metabolic substrates, and antimicrobials, but access is provided by the porins and water-filled channels [12,13]. For example, in Escherichia coli, OmpF and OmpC porins are size restricted and allow the access of hydrophilic charged compounds, including $\beta$-lactams and fluoroquinolone antibiotics. RND (Resistance-Nodulation-cell Division) efflux pumps, such as AcrAB-TolC in E. coli, have a significant role in eliminating antibiotics from the periplasm [12].

OMP proteins are generally classified into high molecular weight OmpC and low molecular weight OmpF. Deletion of OMP proteins could cause bacterial resistance. In Enterobacterales, resistance to carbapenems may be associated with the deleting of OMP proteins, both in the presence and absence of $\beta$-lactamase production. The antibiotic enters the bacterial cells through OMPs, which function as porous channels. When deletion or reduction of these proteins occurs, the permeability of the OM decreases, leading to increased bacterial resistance by blocking access to the cell. Enterobacterales such as Enterobacter cloacae and E. aerogenes show OmpK35 and OmpK36 analogs with OmpC and OmpF, as well as 
OmpD [14]. OMPs are either poorly expressed or their structure is modified, being replaced with other types of protein. In the study by Lee et al., 357 Enterobacter isolates were analyzed. Of these, 31 isolates were resistant to imipenem. In the case of imipenemresistant E. cloacae and E. aerogenes isolates, the expression of OmpD and OmpK35 proteins was also decreased. Thus, it was observed that the primary mechanism of resistance to imipenem was decreased expression of OMPs [14]. In the study by Ye et al., 78 CRE strains were analyzed for carbapenem resistance mechanisms. The authors detected OMPs in CRE strains, demonstrating the relationship between carbapenem resistance and OMP protein deletion [15]. In an observational study of patients with CRE infections treated with meropenem-vaborbactam (MER-VAB), the impact of some porin mutations was evaluated. In the case of isolates harboring porin mutations, the required MICs were higher. The two most common mutations identified in this study among KPC-producing Klebsiella pneumoniae clinical isolates have been shown to have varying effects on the permeability of the OM. Mutant ompK36 with a glycine-aspartic acid insertion at position 134 leads to a constricted inner porin channel, whereas an IS5 promoter insertion results in decreased ompK36 expression $[16,17]$. Consequently, the presence of these mutations may be associated with increased bacterial resistance to MER-VAB therapy. Miao et al. evaluated 67 CRE isolates consisting of K. pneumoniae, K. oxytoca, K. aerogenes, Serratia marcescens, E. cloacae, Raoultella ornithinolytica, and E. coli. Regarding the presence of porin mutations, mutations in OmpK35 and OmpK36 porins were detected in K. pneumoniae. In E. cloacae, S. marcescens, and E. coli, mutations in $\mathrm{OmpF}$ porin were detected. Therefore, resistance to carbapenems can be mediated by the cumulation of enzymatic and non-enzymatic mechanisms in the same strain [18].

\section{Old Antibiotics in Treating CRE Infections}

Although most antibiotics have limitations in the treatment of CRE infections, a number of old antibiotics reintroduced into the therapeutic arsenal in recent years are still active.

For challenging Gram-negative resistant bacteria, polymyxins and tigecycline were considered an option, but resistance to these antibiotics is increasing alarmingly [19-25].

Additionally, phosphomycin and aminoglycosides are used occasionally [26]. Carbapenems still play an important role in treating CRE, either in high doses in combination with other active agents, or in dual therapy. Carbapenems remain some of the most potent classes of antibiotics employed in the last line of defense against nosocomial MDR infections. Carbapenems are BLAs, which differ from penicillin by substituting a carbon atom with a sulfur atom at the $\mathrm{C}-1$ of the five-membered penicillin-like ring and adding a double bond to the $\beta$-lactam nucleus of penicillins. However, the emergence and diversification of $\beta$-lactamases remains a major obstacle to the effectiveness of carbapenems. Old antibiotics such as minocycline, doxycycline, sulfamethoxazole (SXT), and chloramphenicol may be effective against certain CRE isolates [27,28].

A known example is colistin, administered systemically as colistin methane-sulfonate (CMS). Colistin is an important cationic antimicrobial peptide, reintroduced for clinical treatments in the 20th century due to the increase in bacterial resistance and the lack of new effective agents [29]. In the old literature, it was reported that colistin was associated with high rates of toxicity, such as neurotoxicity, nephrotoxicity, and neuromuscular blockade, sometimes leading to fatal consequences [30]. Polymyxins have been associated with several neurotoxic adverse effects, including facial and peripheral paresthesia, dizziness, muscle weakness, confusion, vertigo, and neuromuscular blockade, leading to respiratory failure, convulsions, apnea, and coma [31]. Death was attributed to colistin therapy in less than $5 \%$ of cases [32]. Consequently, colistin use was limited in the late 1970s, except for the treatment of patients suffering from cystic fibrosis (CF) and in topical solutions with other antimicrobial agents to treat ear or eye infections [33]. The spectrum of action of colistin includes Gram-negative MDR and extensively-drug resistant (XDR), especially K. pneumoniae, Acinetobacter baumannii and Pseudomonas aeruginosa. In the International Network for Optimal Resistance Monitoring (INFORM) global surveillance 
program from 2012 to 2015, a total of 24,750 Enterobacteriaceae isolates was investigated, including 24,619 MBL-negative and $131 \mathrm{MBL}$-positive. It was observed that $99.4 \%$ of the Enterobacteriaceae isolates showed susceptibility to the new combination ceftazidimeavibactam (CAZ-AVI), and $82.8 \%$ showed susceptibility to colistin [34]. In recent years, the complex characterization of colistin's pharmacokinetic properties demonstrated its superior activity compared with CMS, thus positioning colistin in a revolutionary period [35]. Currently, the clinical efficacy of colistin can be observed in several clinical trials focused on bacteremia or ventilatory-associated pneumonia (VAP) produced by MDR or XDR pathogens. The main limitations of the published studies are the non-randomized design with a variety of dosages, their retrospective nature, and the absence of a loading dose, whereas the simultaneous administration of other active in vitro antibiotics renders inconclusive the efficacy of monotherapy with colistin [35]. In CRE infections, the combination of colistin with another active antibiotic has been reported to be beneficial in terms of survival, as depicted in the systematic review conducted by Karaiskos et al., which included 19 studies and a total number of 3201 CPE patients [36]. The combination of meropenem with gentamicin or tigecycline or colistin led to a significant minimization of mortality especially in patients with high mortality levels and septic shock [37]. However, many clinicians, taking into consideration the pharmacokinetic/pharmacodynamics limitations of colistin and the development of resistances, favor combination treatment [38].

Colistin resistance may be due to the presence or acquisition of mobile genetic elements, especially plasmids harboring mor genes. In 2015, the first plasmid-mediated colistin resistance was detected in an E. coli strain collected from food animals [39]. However, colistin resistance mediated by plasmids has been reported worldwide [40]. The $m c r-1$ gene acts through modifying the OM lipopolysaccharides (LPS) by an phosphoethanolamine transferase ( $\mathrm{pEtN}$ transferase), which mediates the addition of $\mathrm{pEtN}$ to lipid A [41]. Generally, E. coli strains harboring the $m c r-1$ gene exhibit a low-level of colistin resistance [42]. Another gene involved in colistin resistance is mcr-2 gene, identified by Xavier et al. in E. coli strains in Belgium. The mcr-1 and mcr-2 proteins showed $80.65 \%$ identity [43]. In 2017, Yin et al. described a third mobile colistin resistance gene, $m c r-$ 3 [44]. In 2017, Carrattoli et al. detected a new plasmid-mediated colistin gene, $m c r-4$, in Salmonella on a small, non-self-conjugative plasmid [45]. In 2017, Borowiak et al. described a novel transposon-associated pEtN gene, $m c r-5$, which conferred colistin resistance in d-tartrate-fermenting S. enterica subsp. enterica serovar Paratyphi B [46]. Recently, Carroll et al. have described the $m c r-9$ gene, a novel $m c r$ homolog detected in MDR colistin-susceptible S. enterica serovar Typhimurium strain [47]. Insertion sequences (IS), the smallest $(0.7-2.5 \mathrm{~Kb})$ and simplest transposable elements found in bacteria, are also involved in colistin, as well as carbapenem, resistance [48]. The most common mechanism for developing colistin resistance is inactivation of the $m g r B$ gene in K. pneumoniae, following the transposition of different types of IS, such as IS903, ISKpn26, IS10R, and IS5 [49]. In colistin-resistant strains of Klebsiella sp. and E. coli, alteration of phoP (a member of the two-component system phoP/phoQ involved in bacterial virulence, by mediating the $\mathrm{Mg} 2+$ transport and other physiological processes in several Gram-negative species) and $m g r B$ (the regulator of the phoP/phoQ system) genes and by different IS, such as IS1, ISKpn14, ISKpn28, IS903, IS5, IS3, and ISEc69, can sometimes induce a pan-drug-resistance (PDR) phenotype [50-52].

Fosfomycin, discovered in 1960, was used for a short time and then discontinued due to the appearance of other agents and the development of antimicrobial susceptibility tests. Since then, Fosfomycin has been used in numerous countries for various indications, both in its intravenous (disodium salt) and oral formulations (calcium salt or trometamol). In recent years, the use of Fosfomycin has increased due to the notable incidence of MDR microorganisms for which Fosfomycin constitutes, alone or in combination, a treatment alternative [53,54]. Fosfomycin disodium is mainly used to treat UTIs, particularly those caused by E. coli and Enterococcus faecalis, and, in combination with other antibiotics in the treatment of nosocomial infections caused by resistant Gram-positive and Gram-negative 
bacteria [55]. In the case of oral Fosfomycin, in most European countries it has been used mainly in treating uncomplicated cystitis or other UTIs, particularly those caused by E. coli and E. faecalis. In the USA, the Food and Drug Administration (FDA) has approved oral Fosfomycin only for uncomplicated UTIs. Oral Fosfomycin is approved in several European countries for the therapy of soft-tissue infections and sepsis [56]. However, it should be noted that the intravenous formulation of Fosfomycin is available in five countries in Europe, i.e., Spain, France, Germany, Austria, and Greece [57].

The lack of a consensus regarding the determination of Fosfomycin breakpoints between the Clinical and Laboratory Standards Institute (CLSI) $(\leq 64 \mathrm{mg} / \mathrm{L})[58]$ and the European Committee on Antimicrobial Susceptibility Testing (EUCAST) $(\leq 32 \mathrm{mg} / \mathrm{L})$, the higher MIC required by several microorganisms (Klebsiella spp., Enterobacter spp., Serratia spp., P. aeruginosa) and the differences between the appropriate concentrations needed against Gram-positive and Gram-negative bacteria have resulted in recommended dosages for treating MDR microorganisms infections that vary between 8 and $12 \mathrm{~g} /$ day for Grampositive bacteria and 16 and $24 \mathrm{~g} /$ day for Gram-negative bacteria [59,60]. According to CLSI, the only approved MIC method for testing Fosfomycin susceptibility is agar dilution, using Mueller-Hinton agar plates supplemented with $25 \mathrm{mg} / \mathrm{L}$ of glucose-6-phosphate, whereas broth microdilution MIC testing should not be performed [58]. However, because agar dilution is a laborious and time-consuming method compared to other susceptibility tests, it is not routinely used in microbiology laboratories. Although broth microdilution is not an inadvisable technique for Fosfomycin, it is the base of most automated susceptibility tests. Moreover, different studies have shown a lack of correlation in Fosfomycin susceptibility among broth microdilution, E-test, or disc diffusion tests [61-63]. Ballestero-Téllez et al. investigated the influence of the inoculum size used in agar dilution and broth microdilution, according to CLSI, in Fosfomycin MIC discrepancies. It was observed that susceptibility testing, either in broth or agar, should be done using higher bacterial inocula to capture the bacterial population's whole resistance [64]. More recent studies demonstrate that different susceptibility testing tools can give very different results regarding Fosfomycin resistance, with false positives being an alarming problem that may unnecessarily limit the use of this agent [65-69]. However, these studies show that agar dilution remains the gold standard in determining the MIC values of Fosfomycin.

Phosphomycin has bactericidal activity against susceptible microorganisms and is a unique mechanism for inhibiting the first phase of peptidoglycan synthesis [70]. Phosphomycin disodium has several toxic effects, such as hypocalcemia and increased sodium levels, but some effects can be controlled in the clinic. In in vitro studies, phosphomycin was active against $80 \%$ of Staphylococcus aureus, E. faecium, E. coli, and K. pneumoniae, and less active against CR strains of K. pneumoniae [71]. In the case of 396 strains of K. pneumoniae, isolated from hospitals in Greece, phosphomycin was the third most effective agent [72], results confirmed in a study of strains from hospitals in the USA [73]. Of great interest is the lack of efficacy of phosphosmycin against A. baumannii [74]. The in vitro development of phosphomycin resistance during treatment is a problem in the clinic, so it is recommended to use it in combination therapy $[73,74]$. These studies demonstrate that there is still room for the use of phosphomycin in the clinic against CRE infections [36,75]. However, the biggest challenge related to phosphomycin is the need to target CRE, XDR, and PDR strains. In the case of CRE infections, the use of combination therapy is a basic rule. In the case of phosphomycin, use in combination therapy is recommended to block the selection of resistant bacteria. The recent study called ZEUS [76] led to a change in this dogma, as it was observed that there are groups of patients who respond differently to combination therapy. Regarding the choice of agent for use in combination therapy with phosphomycin, it has been observed that aminoglycosides may increase the efficacy of therapy [77]. However, in a randomized clinical study, the addition of nebulized amikacinphosphomycin to the treatment of VAP did not improve its efficacy [78]. No synergistic action has been observed between phosphomycin and colistin, but there are studies that have shown synergy with other carbapenems [79]. 
Tigecycline has been used in recent years to treat infections caused by CRE and carbapenem-resistant-A. baumannii [80]. Low serum concentration and low penetration of the agent into the epithelial lining fluid have decreased the efficacy of tigecycline [81]. In the case of VAP, hospital-acquired pneumonia (HAP), and infections caused by A. baumannii, it was recommended to use a higher dose of tigecycline. However, all these situations are outside the routine use of tigecycline [82]. Elevated tigecycline concentrations have been observed to be associated with decreased fibrinogen levels and gastrointestinal side effects $[83,84]$. Due to the characteristics of this drug and the high mortality rate when administered as monotherapy to severely ill patients, the use of tigecycline in combination therapy is recommended. Before the advent of state-of-the-art antimicrobial agents, the agents used in combination therapy were colistin and meropenem $[80,85]$. In the era of the new antibiotics, tigecycline will remain a valuable antibiotic, especially in combination therapy. However, further studies are required in order to define new possible combinations.

The emergence of CRE isolates has brought aminoglycosides to the frontline since an aminoglycoside seems the appropriate antimicrobial to which CRE isolates show in vitro susceptibility [86]. The susceptibility of bacterial strains to the action of aminoglycosides varies depending on the presence of aminoglycoside-modifying enzymes (AMEs) that have different affinities for different aminoglycosides [87-90]. Genes encoding AMEs can be transferred as part of gene cassettes in the case of integrons, as well as through conjugation mechanisms [91]. Furthermore, methylation of $16 \mathrm{~S}$ rRNA by $\operatorname{arm} A$, the most prevalent methylase [92], confers a high level of resistance to almost all aminoglycosides [93]. Aminoglycosides are among the most important antibiotic classes used to treat nosocomial infections caused by A. baumannii strains [94]. In general, aminoglycosides are used in combination therapy and as monotherapy in urinary tract infections. In the case of urinary tract infections, the response rate was $88 \%$ when given alone and $64 \%$ when given in combination with other polymyxins [95]. The use of aminoglycoside therapy for infections located in other parts of the body is difficult due to the pharmacological and pharmacokinetic properties of aminoglycosides. The use of aminoglycosides alone for the treatment of CRE infections has been associated with extremely high mortality rates of approximately $80 \%$ [8]. There are also a number of other disadvantages that prevent the optimal use of aminoglycosides. In the case of many MDR and XDR pathogens, borderline susceptibilities against these breakpoints have been observed, a fact further complicated by the difficulty in predicting pharmacokinetic/pharmacodynamics properties of aminoglycosides in critically ill patients $[86,96]$. According to the pharmacokinetic/pharmacodynamics data, monotherapy with aminoglycosides could be very risky for critically ill patients especially in infections in compartments outside the urinary tract $[8,97]$. Short duration courses of aminoglycosides (5-7 days) given as once-daily regimens are associated with less nephrotoxicity compared to multiple daily dosing [98]. When combination treatment is considered, aminoglycosides have been combined with almost all classes of antibiotics [86]. However, more clinical research is needed on these observations.

\section{Current Promising Antibiotics in Treating CRE Infections}

In response to increasing resistance, several new antibiotics have been developed that target KPC (K. pneumoniae carbapenemase)—producing Enterobacteriaceae and other $\mathrm{CRE}$ isolates. Other antibiotics in the final stages of development target pathogens that produce metallo- $\beta$-lactamases (MBL) and MDR A. baumannii [29]. Currently, CAZ-AVI, ceftolozane/tazobactam (CEF-TAZ), MER-VAB, and eravacycline have been included in clinical therapy in America and Europe, while plazomicin has received FDA approval [29].

Selecting an antimicrobial compound for CR Gram-negative infections is almost always challenging, although the degree of difficulty varies depending on the specific clinical scenario. The major issues associated with carbapenemase production are clinical, due to compromising the last-resort antibiotics activity used for treating serious infections, and epidemiological, due to their dissemination into various bacteria across almost all geographic regions and their spread from clinical to environmental reservoirs. An impor- 
tant advancement is the newly launched antibiotics targeting some of the current most problematic Gram-negative pathogens, including CRE. CAZ-AVI and MER-VAB have become important contemporary treatment options for CRE infections in countries where these agents have become available for clinical use [99].

CAZ/AVI, marketed as Allergan, is an intravenous combination of a third-generation cephalosporin and a 2015 FDA-approved $\beta$-lactamase inhibitor. CAZ/AVI is used for the treatment of a wide range of bacterial infections, including cUTI, complicated intraabdominally infections (cIAI), BSI, and pneumonia, as well as hospital-associated and ventilator-associated pneumonia (HAP/VAP) [100-102]. The effectiveness of this combination is based on the addition of avibactam, which is a non- $\beta$-lactam $\beta$-lactamase inhibitor that reinforces the activity of ceftazidime against class A (KPCs) and C (AmpC) $\beta$-lactamases, as well as certain class D enzymes (OXA48) [29]. It is also worth mentioning that avibactam has the advantage of being recycled during successive acylation-deacylation cycles undergone by $\beta$-lactamases [103]. However, CAZ-AVI's effectiveness is often limited by the occurrence of MBLs and mostly class D enzymes [101,104].

The efficacy and tolerance profiles of CAZ/AVI have been investigated in many clinical trials and experiments. A study conducted by the International Network for Optimal Resistance Monitoring (INFORM), which integrated more than 30,000 strains of Enterobacteriaceae isolated from patients with various bacterial infections, revealed an increased susceptibility of these microorganisms to CAZ/AVI combination (99.5\%). According to these observations, the MIC90 for CAZ/AVI was estimated to be about $0.5 \mu \mathrm{g} / \mathrm{mL}$, lower than the MIC90 required for cephalosporins to inhibit the growth of $90 \%$ of bacterial species. Notably, of the 185 cases resistant to CAZ/AVI, one-third were MBL-producers, emphasizing the clinical implications of this molecular mechanism and the need for vigilance in clinical practice [104]. Another study demonstrated the superior efficacy of CAZ/AVI compared to different therapeutic regimens incorporating carbapenem and an aminoglycoside $(\mathrm{CB}+\mathrm{AG})(n=25)$ and a carbapenem with colistin $(\mathrm{CB}+\mathrm{COL})(n=30)$ in managing CR K. pneumoniae strains [105]. It has also been observed that CAZ/AVI can improve 90-day survival rates to $90 \%$ versus $56 \%$ and $63 \%$, respectively, for patients treated with CB $+A G$ and CB + COL [105]. CAZ/AVI showed an excellent safety profile. The nephrotoxicity of CAZ/AVI was much lower (18\%) compared to other combinations, making CAZ/AVI a promising treatment for the therapeutic management of CR K. pneumoniae strains. Notably, another study, led by van Duin et al., 2018, showed that CAZ/AVI was associated with a slight improvement in mortality rate in CRE patients, from $32 \%$ associated with colistin use to $9 \%$ [106].

Several recent studies have also revealed certain molecular mechanisms that may be associated with CAZ/AVI resistance. Some of these studies have shown that mutations in the $\Omega$-loop of the KPC enzyme may lead to higher amounts of ceftazidime hydrolysis that cannot be overcome by avibactam. Other studies have suggested the existence of alternative mechanisms involving either the production of MBLs [104], mutations in different KPC enzymes [107,108], decreased outer membrane permeability, or enhanced drug efflux [109]. However, a relatively recent study led by Huang et al. demonstrated that the optimal therapeutic approach for CAZ-AVI-resistant isolates depend on the antibiotic resistance mechanism triggered. Notably, it has been shown that the combination of CAZ/AVI and meropenem is active and may suppress the recurrence of CAZ/AVI-resistant, meropenemsusceptible KPC-producing K pneumoniae isolates. Besides, they reported that clinically achievable CAZ/AVI concentrations might be satisfactory in suppressing the regrowth of CAZ/AVI resistant KPC-producing K. pneumoniae with Omp mutations and higher bla $\mathrm{KPC}$ levels [110].

CEF-TAZ is a new semisynthetic antipseudomonal cephalosporin used in the treatment of cUTIs, cIAF, and HAP. CEF is an oxyimino-amino-thiazolyl cephalosporin, very similar structurally to $C A Z$ but with a modified side chain that contributes to its stability in the presence of AmpC $\beta$-lactamases, prevents the hydrolysis of the $\beta$-lactam ring, and thus confers potent activity against Enterobacteriaceae strains [111]. CEF-TAZ has in vitro ac- 
tivity against Streptococcus species and has diminished activity against $S$. aureus strains. CEF-TAZ also has improved activity against a significant number of species belonging to the Enterobacteriaceae family such as E. coli, K. pneumoniae, Enterobacter spp., Citrobacter spp., Serratia spp., K. oxytoca, and P. mirabilis $[112,113]$. It has also been demonstrated that CEF-TAZ has in vitro activity against Bacteroides fragilis, Prevotella, and Fusobacterium spp. The in vitro activities of CEF-TAZ were determined for 1774 isolates of Enterobacteriaceae collected by 30 medical centers from the China Antimicrobial Surveillance Network (CHINET) in 2017. CEF-TAZ demonstrated potent activity against almost all Enterobacteriaceae, including K. pneumoniae and E. coli, with a susceptibility rate of $94.6 \%$ [111]. In the study conducted by Saran et al., CEF-TAZ activity was investigated in the case of 60 Enterobacteriaceae strains isolated from samples obtained from hematological patients in Poland. The results demonstrated that this combination could be a good option in treating CRE infections [114]. Castanheira et al. evaluated the activity of CEF-TAZ against 2362 Enterobacteriaceae isolates obtained from respiratory tract specimens from patients hospitalized in the United States during 2013 to 2015. CEF-TAZ inhibited 90.6\% of the 2362 Enterobacteriaceae isolates, including K. pneumoniae, K. oxytoca, E. aerogenes, E. cloacae, E. coli and Proteus mirabilis [115]. In another study, 733 ESBL Enterobacteriaceae isolates including 486 E. coli, $190 \mathrm{~K}$. pneumoniae and $42 \mathrm{E}$. cloacae were investigated regarding susceptibility to CEF-TAZ. CEF-TAZ inhibited $95.5 \%$ of the E. coli isolates but only $83.0 \%, 64.3 \%$, and $80.0 \%$ of K. pneumoniae and E. cloacae [116].

Relebactam and varbobactam, some of the best-studied BLIs, showed strong in vitro efficiency over class A and C $\beta$-lactamases [117]. Recently, they have become increasingly used in the therapeutic management of CRE in combination with carbapenems, such as imipenem (with relebactam: IMI/REL) and meropenem (with varbobactam: MER/VAB) [118,119]. IMI/REL gained FDA approval in July 2019, whereas MER/VAB was approved for use in the USA in 2017 [118]. Interestingly, it has been observed that adding REL, an AVI-like BLI, to IMI can increase the susceptibility to IMI of CRE isolates from $8 \%$ to $88 \%$ [120]. Similar observations were made on strains of P. aeruginosa [121,122]. However, information on CRE susceptibility levels to IMI/REL is conflicting: for example, a study conducted by Livermore et al. demonstrated a modest efficacy of IMI/REL on K. pneumoniae VIM, IMP, and NDM-producing strains [123]; in contrast, two other independent studies reported a $100 \%$ susceptibility to K. pneumoniae producing KPC-2 and KPC-3 isolates $[120,124]$. IMI/REL also proved its potency against CAZ/AVI-resistant K. pneumoniae isolates that harbored OXA-48-type carbapenemase; yet, this study highlighted that IMI/REL and CAZ/AVI have overlapping spectra of action and that these observations can be harnessed to improve the therapeutic management of CRE infections [120]. In the study conducted by Yang et al., a total of 8781 Enterobacteriaceae isolates were collected from 22 hospitals across 7 geographic regions of China. The most frequently identified Enterobacteriaceae species was E. coli (53.3\%), followed by K. pneumoniae (33.6\%) and E. cloacae (6.2\%). The Enterobacteriaceae isolates showed $95.2 \%$ overall susceptibility to IMI/REL, demonstrating the effectiveness of IMI/REL treatment [125]. In a recent study (SMART Surveillance Europe 2015-2017), a total of 11,564 Enterobacteriaceae isolates from 22 countries has been investigated in terms of susceptibility to IMI/REL. IMI/REL inhibited $\geq 99 \%$ of E. coli, K. oxytoca, Citrobacter freundii and K. aerogenes isolates, and $92.2-97.4 \%$ of K. pneumoniae, E. cloacae and S. marcescens [126].

Another recent addition to the therapeutic arsenal against CRE infections is the meropenem-varbobactam $(\mathrm{M} / \mathrm{V})$ combination. This combines a carbapenem with varbobactam (or RPX-7009), a pharmacophore-based boronic acid BLI active against Ambler class A and C $\beta$-lactamases. The FDA approved $\mathrm{m} / \mathrm{V}$, marked as Vabomere, in August 2017 to treat cUTIs, including pyelonephritis caused by CRE in patients 18 years of age and older [118,127]. The M/V combination's efficacy and safety were tested in two clinical trials, TANGO I and TANGO II, showing results as good as those of other compounds and antibacterial combinations used in the management of CRE infections [128,129]. Recently, however, M/V has gained approval from the European Medicines Agency (EMA) for the 
treatment of cUTI, acute pyelonephritis, cIAIs, HAP, VAP, as well as other infections caused by aerobic Gram-negative pathogens in adults with limited treatment options [130].

Cefepime/zidebactam (WCK 5222) revealed in vitro antimicrobial activity against Enterobacteriaceae. Zidebactam is a non- $\beta$-lactam bicyclo-acyl hydrazide with two mechanisms of action, direct inhibition of $\beta$-lactamases and PBP2 inhibition [131]. The spectrum of action is broad, acting against all four $\beta$-lactamase classes (A, B, C, and D), except MBLs. Zidebactam binds to PBP2 with high affinity, while cefepime binds PBP3 and less PBP2 and PBP1a/1b. The primary mechanism of action of zidebactam/cefepime is the improvement of the antibiotic's action by complementary binding to PBPs [132]. In the study conducted by Karlowsky et al., the in vitro susceptibility of 1018 clinical isolates of noncarbapenem-susceptible Enterobacterales, collected worldwide (49 countries) from 2014 to 2016 , to cefepime-zidebactam has been investigated. Cefepime-zidebactam inhibited 98.5\% of non-carbapenem-susceptible Enterobacterales. Moreover, cefepime-zidebactam was active against the majority of Enterobacterales ( $\geq 95 \%)$ isolates that were resistant to ceftazidime-avibactam CEF-TAZ, IMI-REL, and colistin. The results from this study support the continued development of cefepime-zidebactam as a potential therapy for infections caused by Enterobacterales [133]. A total of 2228 non-duplicate clinical isolates of Enterobacterales were collected from 45 medical centers across China in the CHINET Program in 2018. The study aimed to determine the activities of cefepime-zidebactam by broth microdilution as recommended by the Clinical and Laboratory Standards Institute. Cefepime-zidebactam demonstrated potent activity against almost all Enterobacterales (MIC50/90, 0.125/1 mg/L), including bla KPC-2-positive Enterobacterales and bla NDMpositive Enterobacterales [134]. The safety, efficacy, and tolerability of these agents have already been performed in phase I by intravenous administration to healthy adult patients (ClinicalTrials.gov registration no. NCT02674347 and NCT02707107). A clinical study conducted by Rodvold et al. analyzed the zidebactam/cefepime levels in alveolar macrophage, plasma, and epithelial-lining fluid. Intravenous administration of these compounds led to moderate adverse reactions. However, the administration of WCK 5222 proved safe and well-tolerated by patients. This study demonstrated the possibility of using this combination to treat nosocomial pneumonia [135]. Cefepime-zidebactam is highly active against MBL-expressing CREs [136].

Ceftaroline/Avibactam (CPA) is a promising combination that can be used to control the spread of antibiotic-resistant pathogens. This formulation combines ceftaroline, a fifth-generation broad-spectrum cephalosporin, active on Gram-positive and Gramnegative organisms, with avibactam, an antibiotic derived from diazabicyclo-octane that can reversibly inhibit several $\beta$-lactamases, including Ambler class A, class C, and certain class D enzymes [137]. The FDA has approved Ceftaroline fosamil (Teflaro), as has the European Medicines Agency (EMA), for the treatment of acute bacterial skin and skin structure infections caused by MRSA (Methicillin-Resistant S. aureus) and communityacquired pneumonia (CAP) caused by MSSA (Methicillin-Susceptible S. aureus), MRSA, and Gram-negative bacteria [138]. The prodrug, ceftaroline fosamil, is converted to plasma in the active form; hence it binds to plasma proteins and is transported to specific sites where it exerts its antimicrobial effects binding with high affinity to all 6 PBPs, especially PBP2a [138,139]. Ceftaroline also has activity on many species of Enterobacteriaceae but, like other cephalosporins, it is not potent on species producing ESBL and carbapenems [140]. However, the use of ceftaroline in conjunction with avibactam (NXL104) can significantly expand the action spectrum of the combination on several MDR pathogens while maintaining its anti-staphylococcal spectrum of action [140].

CPA is being evaluated to treat bacterial infections caused by Gram-negative and Gram-positive pathogens that produce $\beta$-lactamases, CRE being of particular interest. One of the most important studies to evaluate the clinical efficacy of CPA in Enterobacteriaceae is that led by Castanheira et al. Among others, the authors analyzed the antimicrobial capabilities of the combination in $272 \beta$-lactamase-producing Enterobacteriaceae strains, which included isolates producing ESBLs (33), carbapenemases (69), AmpC en- 
zymes (36), and combinations of two or more enzymes (99) [140]. In the strains of Klebsiella spp. and E. coli, the most commonly reported serine carbapenemases were KPC-2 (32 strains), KPC-3 (23 strains), SME-1/-2 (seven strains), OXA-48 (five strains), KPC-4 (one strain), and NMC-A (one strain). Thirty-seven strains have been identified to co-produce AmpC enzymes and carbapenemases [140]. Interestingly, CRE isolates showed higher CPA MIC values than those of ESBL- and AmpC-producing strains (MIC50, $0.5-1 \mu \mathrm{g} / \mathrm{mL}$ versus $0.12 \mu \mathrm{g} / \mathrm{mL}$ ). CPA inhibited $84 \%$ of Enterobacteriaceae strains at MIC $\leq 1 \mu \mathrm{g} / \mathrm{mL}$, with only three carbapenemase-producing strains requiring CPA MIC values higher than $>4 \mu \mathrm{g} / \mathrm{mL}$ [140]. Species that co-produce AmpC enzymes and carbapenemases were less susceptible to antimicrobial combinations than serine CPE strains (MIC50, $1 \mu \mathrm{g} / \mathrm{mL}$ compared to $0.5 \mu \mathrm{g} / \mathrm{mL}$ ). As expected, ceftaroline/avibactam showed limited activity on MBL-producing species, especially the notorious VIM and IMP variants (MIC50 > $32 \mu \mathrm{g} / \mathrm{mL}$ ) [140]. In parallel, the same group of authors tested the effect of ceftaroline/avibactam on a collection of 493 CPE strains, including E. coli, Klebsiella spp. and P. mirabilis isolates [141]. Notably, the pharmacological combination was shown to be potent in inhibiting the growth of $98.2 \%$ of strains at $\leq 0.5 \mu \mathrm{g} / \mathrm{mL}$. In contrast, all strains were inhibited at a MIC $\leq 2 \mu \mathrm{g} / \mathrm{mL}$ of this combination [141]. Another recent study led by Khalid et al. revealed that administration of avibactam in conjunction with ceftaroline at $4 \mu \mathrm{g} / \mathrm{mL}$ might expand its spectrum of activity on K. pneumoniae strains bearing carbapenems and multiple $\beta$-lactamases and OmpK35 and OmpK36 porin defects [142]. Therefore, all these observations potentiate that ceftaroline/avibactam may be a useful therapeutic option in the management of CPE strains, supporting the clinical development of this pharmacological combination.

Another recently approved antibiotic in the fight against CRE is cefiderocol, also known as S-649266 [143]. Cefiderocol is a parenteral cephalosporin siderophore that shares some structural similarities with cefepime and ceftazidime. However, according to the latest data, cefiderocol has been noted as one of the most potent antimicrobial compounds in the fight against fermenting and non-fermenting Gram-negative pathogens, including CRE [144]. Cefiderocol was approved in September 2019 by the FDA to treat complicated UTIs and is currently under investigation in phase III trials regarding its effectiveness against pneumonia and other infections caused by CRE [143]. The structural peculiarities of cefiderocol give it a unique mechanism of action; cefiderocol can exploit the siderophore-iron complex pathway to penetrate the OM of Gram-negative organisms as an alternative mechanism to passive diffusion through membrane porins [139]. Once in the periplasmic space, cefiderocol dissociates from the iron complex and binds preferentially to PBP3, resulting in inhibition of bacterial growth [145]. Notably, the combination of a cephalosporin with catechol moiety has been shown to generate an antibacterial compound with many improved pharmacological properties, potent over various $\beta$-lactamases, including KPC, NDM, VIM, IMP, OXA-58, OXA-48-like, and OXA- 51-like carbapenemases, as well as ESBLs such as CTX-M [143].

We will focus here on the most relevant clinical trials and trials that have evaluated the efficacy of cefiderocol in CRE isolates. A meta-analysis conducted by Wu et al. on a worldwide collection of Gram-negative isolates revealed that cefiderocol is active on Enterobacterales spp. at MICs between $\leq 0.002$ to $128 \mu \mathrm{g} / \mathrm{mL}$, while CRE isolates showed cefiderocol susceptibility at MICs ranging between 0.008-8 $\mu \mathrm{g} / \mathrm{mL}$ [143]. Moreover, in the ARGONAUT-I study (Antibacterial Resistance Leadership Group (ARLG) Reference Group for the testing of Novel Therapeutics), cefiderocol demonstrated in vitro superior antibacterial activity cefepime, aztreonam, ceftazidime, CAZ/AVI, and ceftolozane/tazobactam in combating CRE infections [146]. In this study, the authors also observed that the activity of cefiderocol on CRE varied depending on the type of carbapenemase expressed, with MICs of $1 \mathrm{mg} / \mathrm{L}$ for strains expressing OXA-48-like genes, $2 \mathrm{mg} / \mathrm{L}$ for KPC-3, and $8 \mathrm{mg} / \mathrm{L}$ for strains producing NDM, KPC-2, and ESBLs [146]. In line with these observations, Karlowsky et al. showed that at a concentration of $\leq 4 \mathrm{mg} / \mathrm{L}$, cefiderocol possesses in vitro activity against over $99 \%$ of Enterobacteriaceae strains resistant to CAZ/AVI 
ceftolozane/tazobactam, cefepime, ciprofloxacin, and colistin [147]. Recent studies on animal infection models also support the potential utility of cefiderocol in treating infections caused by CRE $[148,149]$. However, the most substantial evidence regarding the therapeutic utility of cefiderocol comes from clinical trials. A recently ended, randomized, open-label, multicenter, pathogen-focused, descriptive, phase 3 trial (NCT02714595) offered remarkable insights regarding the efficacy and cefiderocol compared to best available therapy for the management of life-threatening infections caused by CR-Gram-negative bacteria, including CRE [150]. Cefiderocol showed a therapeutic efficacy similar to that of the best available therapy in the analyzed patient population. Notably, mortality was higher in the group of patients receiving cefiderocol, especially in the subset of patients with Acinetobacter spp. Infections [150]. However, preliminary data from a randomized, double-blind trial (APEKS-NP) in patients with nosocomial pneumonia due to carbapenem-susceptible Gram-negative pathogens showed a similar rate of mortality as compared to meropenem, providing some reassurance in the overall benefit/risk assessment [151]. Collectively, these observations support the use of cefiderocol as a potential therapy in treating CR infections while emphasizing the need to use this drug in patients without other therapeutic alternatives and in the absence of poor prognosis indicators. Undoubtedly, shortly we will find more information on the efficacy and tolerability of cefiderocol in clinical trials now underway (NCT03869437).

Aztreonam/avibactam (AZT/AVI) is a unique compound with activity against CPE and MBLs. AZT is mainly resistant to the action of MBLs; however, aztreonam can be readily hydrolyzed by Ambler class A or class C $\beta$-lactamases [152]. Notably, avibactam can inhibit these secondary $\beta$-lactamases, which is why the AZT-AVI combination may be a valuable therapeutic strategy against $\mathrm{M} \beta \mathrm{L}$-producing organisms with secondary $\beta$ lactamases. The combination of AZT-AVI is currently being studied in clinical trials to investigate its efficacy on M $\beta$ L-related CRE infections [153]. However, both components of the combination are FDA-approved: aztreonam and CAZ/AVI, respectively. Only by using these approved drugs can patients benefit from the AZT/AVI combination; this procedure was also recently included in the Sanford guide for antimicrobial therapy of CRE infections [153]. Although the use of AZT in conjunction with CAZ-AVI is permitted for clinical use, there are still many details to elucidate regarding in vitro antimicrobial susceptibility testing (AST) of this combination or AZT-AVI [153,154].

Several studies have shown the superior efficacy of aztreonam/avibactam in CRE isolates compared to other combinations available to manage these infections. One of these studies, conducted by Chew et al., showed that the aztreonam/avibactam combination could restore susceptibility to aztreonam in a CPE collection of 13 E. coli, $44 \mathrm{~K}$. pneumoniae, seven Citrobacter freundii, and six E. cloacae isolates [152]. In the first instance, 23 CPEs carrying bla $\mathrm{KPC}_{2}$ and bla $\mathrm{NDM}_{-1}$ or bla $\mathrm{NDM}_{-1}$, bla $\mathrm{NDM}_{-5}$, and bla $\mathrm{OXA}-48$ gene variants were tested against combinations of aztreonam and meropenem with avibactam [152]. All the strains were non-susceptible to meropenem and aztreonam; however, the addition of avibactam restored the susceptibility of $95.7 \%$ of the species to aztreonam and $4 \%$ to meropenem. The other 48 CPEs were further tested against aztreonam and avibactam, administered alone or combined [152]. All isolates were non-susceptible to aztreonam; notably, the addition of avibactam restored their sensitivity to aztreonam. Overall, for the entire collection of 70 isolates, the combined MIC90s were $>64 \mathrm{mg} / \mathrm{L}$ for aztreonam and $2 \mathrm{mg} / \mathrm{L}$ for aztreonamavibactam combinations, this dose of aztreonam-avibactam formulation blocking bacterial growth for approximately 98.6\% of CRE strains [152]. Another study, led by Kim et al., analyzed the in vitro activity of CAZ-AVI and AZT/AVI, respectively, while evaluating the inoculum effect on CRE strains containing both CP-CRE and non-CP-CRE strains [155]. CASE/AVI and AZT/AVI MICs were evaluated by broth microdilution using standard $\left(1 \times 10^{5} \mathrm{CFU} / \mathrm{mL}\right)$ and high inocula $\left(1 \times 10^{7} \mathrm{CFU} / \mathrm{mL}\right)$ in a batch of $81 \mathrm{CR}$ E. coli and K. pneumoniae strains. The inoculum effect was defined as an $\geq 8$-fold MIC increase with high inoculum. As many as $43 \%$ of the strains analyzed were CP-CRE, of which $34 \%$ had MBL. Notably, CAZ/AVI was active on 73\% of the CRE isolates, while AZT/AVI had a 
lower MIC ( $\leq 8 \mu \mathrm{g} / \mathrm{mL}$ ) against $95 \%$ of the CRE isolates. However, compared to CAZ/AVI, AZT / AVI was much less potent against non-CP-CRE isolates. The inoculum effect was much more prominent with AZT/AVI than in CAZ/AVI (47\% and $18 \%$, respectively), especially in K. pneumoniae isolates. However, the use of the AZT / AVI combination should be performed with caution in the clinical context. The presence of a substantial inoculum effect may contribute to the clinical failure of high-inoculum infections treated with AZT/AVI [155].

A promising therapeutic strategy in the fight against CRE, not yet validated for use in the clinical context, is to combine meropenem with nacubactam, also known as RG6080 or OP0595 [156]. Nacubactam, a bridged diazabicyclo-octanone $\beta$-lactamase inhibitor, acts on class $A$ and class $C \beta$-lactamases while exhibiting minor activity on class D enzymes [157]. Nacubactam has an increased structural analogy with avibactam but differs from it by adding an aminoethoxy group to the carbamoyl side chain of avibactam. This change is most likely responsible for the intrinsic antimicrobial activity of nacubactam when administered as monotherapy [158]. Nacubactam is documented as inhibiting PBP2 in several Enterobacteriaceae strains [159]. The combination of nacubactam with other $\beta$ lactam agents acting against other PBPs can considerably increase the antimicrobial activity of nacubactam, extending its spectrum of action on Enterobacteriaceae producing ESBLs, AmpCs, KPCs, and MBLs, in addition to those porin-defective ESBL- and AmpC-producing Enterobacteriaceae $[157,160]$.

Meropenem/nacubactam is currently being evaluated for its efficacy against CRE strains. Although the data are relatively few, the results obtained are encouraging. Barnes et al. examined the susceptibility of a collection of CR K. pneumoniae and E.coli strains harboring bla $\mathrm{KPC}_{-2}$ and bla KPC-3 $\beta$-lactamases to a panel of antibiotics, including meropenemnacubactam at a ratio of 1:1 [158]. For the 44 CR K. pneumoniae strains, the MICs for these drugs varied within the collection; however, all strains were susceptible to meropenem/ nacubactam. The RB1324 strain, which harbored bla KPC-3 genes, showed an extremely high MIC for nacubactam ( $>256 \mathrm{mg} / \mathrm{L})$, most likely due to a mutation in PBP2 [158]. However, the addition of meropenem significantly reduced MIC to $0.5 \mathrm{mg} / \mathrm{L}$, potentiating that the meropenem/nacubactam combination is superior to other BLIs in the treatment of highresistant K. pneumoniae strains. In parallel, administration of meropenem/nacubactam resulted in a modest decrease in MICs for meropenem in E. coli strains producing the KPC variants. The most pronounced effect of adding nacubactam was observed for the strain expressing pBR322-KPC-2 wild type, which showed an approximately 30 -fold reduction in MIC than MIC meropenem alone. Strains expressing P104K, V240G, V240K, and K234R variants showed a slight increase in meropenem/nacubactam MIC than strains expressing KPC-2. In contrast, foreign E. coli expressing the K234R variant showed no changes in meropenem MIC by referencing KPC-2 producing strain [158]. Another study, led by Monogue et al., demonstrated the therapeutic efficacy of the meropenem/nacubactam combination in Enterobacteriaceae-infected murine models of complicated UTIs, including NDM, KPC, OXA, CTX-M, SHV, and TEM enzyme-producing isolates. This research emphasizes that this promising combination is likely to be included soon in the antimicrobial armamentarium in the fight against CRE [156].

Plazomicin (ACHN-490) is a next-generation semisynthetic aminoglycoside derived from sisomicin [161]. Sisomicin was isolated from Micromonospora inyoensis in 1970 and presents a chemical structure similar to that of gentamicin. Despite the increased spectrum of activity of sisomicin compared with other clinically available aminoglycosides at the time, it was susceptible to many AMEs, limiting its use [161]. In contrast to the traditional aminoglycosides, plazomicin has several structural modifications. Plazomicin does not contain hydroxyl groups in the $3^{\prime}$ and $4^{\prime}$ positions, which protects it from two AMEs: O-nucleo-tidyl-transferase ANT $\left(4^{\prime}\right)$, which impacts both amikacin and tobramycin, and O-phosphotransferase $\mathrm{APH}\left(3^{\prime}\right)$, which only impacts amikacin $[162,163]$. The introduction of the unsaturated hydroxyethyl group at position $6^{\prime}$ on the plazomicin molecule provides protection against $\mathrm{N}$-acetyltransferase $\mathrm{AAC}\left(6^{\prime}\right)$, which causes resistance to to- 
bramycin gentamicin and amikacin [163]. Lastly, the plazomicin structure has an N-1 substitution with 4-amino-2-hydroxybutanoic acid, which blocks AAC(3) and ANT(2"), which both cause gentamicin and tobramycin resistance, and $\mathrm{APH}\left(2^{\prime \prime}\right)$, which causes resistance to gentamicin, tobramycin, and amikacin [164]. Plazomicin (Zemdri; Achaogen, Inc., South San Francisco, CA, USA) demonstrates in vitro activity against multidrug-resistant gram-negative pathogens and retains activity against AME-producing bacteria, in contrast to other available aminoglycosides [165-170]. Due to its enhanced spectrum of activity, the FDA designated plazomicin as a Qualified Infectious Disease Product and it was approved in 2018 to treat complicated urinary tract infections, including pyelonephritis [171]. It has been observed that plazomicin is more active than other aminoglycosides against KPC and OXA-48 producers but shows more variable activity against NDM-1-producing isolates due to the common co-production of 16S-RNA methylases in these isolates [172,173]. Cox et al. led a study regarding the activity of plazomicin on AMEs-producing E. coli strains. It was observed that the majority of AMEs did not impact plazomicin potency, with the exception of AAC $\left(2^{\prime}\right)$-Ia (16-fold increase in minimum inhibitory concentration, MIC) and APH( $\left.2^{\prime \prime}\right)$-IVa (4- to 8-fold increase in MIC). The expression of $16 \mathrm{~S}$ methylases also led to highly elevated plazomicin MICs (ranging from 64 to $>512 \mu \mathrm{g} / \mathrm{mL}$ ) [174].

The in vivo antimicrobial activity of plazomicin against Enterobacteriaceae has been studied in various animal models, including murine systemic [175], pulmonary [176] and UTI models [175], African green monkeys [177], and cynomolgus macaques (CM) [178].

Clinical trials completed to date include phase I, phase II and phase III clinical trials. Gall et al. conducted a phase 1, randomized, double-blind, crossover study aiming to assess the potential effects of plazomicin on cardiac repolarization (NCT01514929). Fiftysix healthy adults ( 24 men, 32 women) received a single therapeutic dose of plazomicin ( $15 \mathrm{mg} / \mathrm{kg}$ administered by 30 -min intravenous infusion), a single supratherapeutic dose of plazomicin ( $20 \mathrm{mg} / \mathrm{kg}$ administered by 30 -min intravenous infusion), placebo, or oral moxifloxacin (400 mg). Model-derived pharmacokinetic parameters and safety findings were generally consistent with other reported plazomicin studies. It was observed that therapeutic and supratherapeutic doses of plazomicin had no clinically significant effect on cardiac repolarization and were generally well tolerated [179]. Connolly et al. evaluated the efficacy and safety of plazomicin in a double-blind, comparator-controlled, phase 2 study in 145 adults with complicated UTI or acute pyelonephritis. Patients were randomized 1:1:1 to receive intravenous plazomicin ( 10 or $15 \mathrm{mg} / \mathrm{kg}$ of body weight) or intravenous levofloxacin $(750 \mathrm{mg})$ once daily for five days. The phase 2 clinical trial results showed that the administration of plazomicin once daily for five days was an effective treatment in adult patients with cUTI, including acute pyelonephritis. Microbiological eradication was achieved in over $85 \%$ of plazomicin-treated patients in the ME population, and the investigator assessed $80 \%$ of patients who received the $15-\mathrm{mg} / \mathrm{kg}$ dose of plazomicin to be clinically cured with complete resolution of baseline signs and symptoms of infection [180]. Kuti et al. conducted a Phase 3, randomized study (CARE) evaluating the efficacy and safety of plazomicin-based combination therapy compared with colistin-based combination therapy to treat patients with bloodstream infections HAP and VAP due to CRE. These analyses included 18 patients enrolled in Cohort 1 of the CARE Study who were randomized to receive plazomicin combined with either tigecycline or meropenem, provided that plazomicin achieved its requisite pharmacodynamic exposure in all 15 patients which met the inclusion criteria [181]. Wagenlehner et al. conducted a multicenter, multinational, randomized, double-blind, phase 3 trial to demonstrate the potential activity of plazomicin and meropenem in the treatment of cUTI, including acute pyelonephritis. The results demonstrate that plazomicin was non-inferior to meropenem in treating patients with cUTIs, including acute pyelonephritis, with higher microbiologic eradication rates [182].

Eravacycline is a new, fully synthetic fluorocycline developed to treat infections caused by MDR microorganisms, such as CRE, MRSA, ESBL-producing Enterobacteriaceae, and VRE; in 2018, this fluorocycline was approved by the FDA and marketed as Xerava [183]. Eravacycline, formerly TP-434, was designed to overcome two of the main resistance mechanisms 
common to the tetracycline class: ribosomal protection, commonly seen in gram-positive organisms, and active drug efflux, common in both Gram-positive and Gram-negative organisms [184]. The safety and pharmacokinetics of eravacycline were investigated in a phase 1 clinical study [185] that included 20 patients and in a randomized phase two, double-blind, active control study, published in 2014 [186]. Two-phase 3 clinical trials (e.g., IGNITE1 and IGNITE4) recently evaluate the safety and efficacy of eravacycline $[183,187]$.

Omadacycline (NUZYRA ${ }^{\circledR} /$ PTK 0796) is a new amino-methyl-cycline developed by Paratek Pharmaceuticals (Boston, MA, USA). It is an intravenous and oral antibiotic therapy, approved (2018) by the FDA, for clinical use in acute bacterial skin and skin structure infections and community-acquired bacterial pneumonia $[188,189]$. Recent microbiological data demonstrate omadacycline's in vitro activity against multiple pathogens, including MSSA, MRSA, S. pneumoniae, $\beta$-hemolytic streptococci, VRE, Enterobacterales, Legionella pneumophila, Mycoplasma spp., Ureaplasma spp., Bacteroides spp., and Clostridioides difficile [190-192].

The in vivo antibacterial activity of omadacycline has been evaluated in several animal models, including neutropenic murine lung infection, thigh infection, and intraperitoneal challenge models [193-195].

Omadacycline has been investigated in several completed clinical trials to treat various clinical conditions. One completed phase II trial evaluated the activity of omadacycline on complicated skin and skin structure infection (cSSSI, NCT03716024) [196] and three phase III clinical trials investigated the activity of omadacycline on complicated skin and skin structure infection and community-acquired bacterial pneumonia. The phase III trials, OASIS-1 (Omadacycline for Acute Skin and Skin Structure Infections Study, NCT02378480), OASIS-2 (NCT02877927), and OPTIC (Omadacycline for Pneumonia Treatment in the Community, NCT02531438), established the non-inferiority of omadacycline to linezolid (OASIS-1, OASIS-2) and moxifloxacin (OPTIC) [197-199].

Given their broad spectrum of activity against clinically relevant Gram-positive and Gram-negative bacteria and availability as intravenous and oral formulations, fluoroquinolones are amongst the most commonly utilized classes of anti-bacterials for treating infectious diseases [200]. Delafloxacin [Quofenix ${ }^{\mathrm{TM}}$ (EU); Baxdela ${ }^{\circledR}$ (USA)] is a novel, fully synthetic anionic fluoroquinolone with a modified quinolone structure that improves its spectrum of antibacterial activity, pharmacokinetic profile, and toxicity profile [201]. The chemical structure of delafloxacin is different from other fluoroquinolones based on three notable changes: a heteroaromatic ring at the N1 position that enhances its antibacterial activity, a weak polarity at the $\mathrm{C} 8$ position, and the absence of a primary group at the C7 position [200,202].

Delafloxacin is approved in several countries for intravenous and oral formulations to treat adults with acute bacterial skin and skin structure infections (featured indication) and/or community-acquired bacterial pneumonia [203]. Delafloxacin has demonstrated greater in vitro potency than levofloxacin against most gram-positive pathogens, including retaining activity in many levofloxacin-non-susceptible isolates. Notably, delafloxacin is 32-fold more active than levofloxacin against MRSA isolates [204] and is active both in vitro and in clinical infections against most isolates of E. coli, K. pneumoniae, E. cloacae, and P. aeruginosa, with activity similar to ciprofloxacin.

Several phase clinical trials, including phase I, II and III trials, demonstrate that the clinical efficacy of delafloxacin is as high as that of the comparator drugs (e.g., vancomycin, moxifloxacin, ceftriaxone) in the treatment of acute bacterial skin and skin structure infections and community-acquired bacterial pneumonia, including MRSA-associated infections; furthermore, this antibiotic is as well-tolerated as the comparators [205-211].

A brief summary of these promising agents that include the mechanism of action, market availability, indications and limitations can be found in Table 1. 
Table 1. Current promising antibiotics in treating carbapenem-resistant Enterobacterales (CRE) infections ${ }^{1}$.

\begin{tabular}{|c|c|c|c|c|}
\hline Drug & Mechanism of Action & $\begin{array}{l}\text { Commercially } \\
\text { Available }\end{array}$ & Indications & Limitations \\
\hline Ceftazidime/avibactam & $\begin{array}{c}\text { Cell wall } \\
\text { synthesis inhibitor }\end{array}$ & $\begin{array}{l}\text { Yes; FDA-approved in } \\
2015 \text { as Allergan }\end{array}$ & $\begin{array}{l}\text { cUTI, cIAI, } \\
\text { BSI, pneumonia }\end{array}$ & Occurrence of resistance \\
\hline Ceftolozane/tazobactam & Inhibition of PBPs & $\begin{array}{c}\text { Yes; FDA-approved in } \\
2014 \text { (Zerbaxa) }\end{array}$ & cUTI, cIAI & Occurrence of resistance \\
\hline Meropenem/varbobactam & $\begin{array}{c}\text { Cell wall } \\
\text { synthesis inhibitor }\end{array}$ & $\begin{array}{l}\text { Yes; FDA-approved in } \\
2017 \text { as Vabomere }\end{array}$ & $\begin{array}{l}\text { cUTI, cIAI, } \\
\text { BSI, pneumonia }\end{array}$ & Ocurrence of resistance \\
\hline Ceftaroline/avibactam & Inhibition of PBPs & $\begin{array}{l}\text { Under clinical } \\
\text { investigation }\end{array}$ & cUTI & $\begin{array}{l}\text { Occurrence of resistance } \\
\text { due to mutations in } \\
\text { KPC-producing } \\
\text { Enterobacteriaceae }\end{array}$ \\
\hline $\begin{array}{c}\text { Cefepime/Zidebactam } \\
\text { (WCK 5222) }\end{array}$ & $\begin{array}{c}\text { Direct inhibition of } \\
\beta \text {-lactamases or } \\
\text { PBP2 inhibition }\end{array}$ & $\begin{array}{l}\text { Under clinical } \\
\text { development }\end{array}$ & cUTI, cIAI, SI, pneumonia & Ocurrence of resistance \\
\hline $\begin{array}{l}\text { Imipenem/cilastatin- } \\
\text { relebactam }\end{array}$ & $\begin{array}{c}\text { Renal dehydro-peptidase } \\
\text { inhibitor } / \beta- \\
\text { lactamase inhibitor }\end{array}$ & $\begin{array}{l}\text { Yes; FDA-approved in } \\
2019 \text { as Recarbrio }\end{array}$ & cUTI, cIAI, pneumonia & $\begin{array}{l}\text { Severe hypersensitivity } \\
\text { reactions }\end{array}$ \\
\hline Aztreonam/avibactam & $\begin{array}{c}\text { Cell wall } \\
\text { synthesis inhibitor }\end{array}$ & $\begin{array}{l}\text { Under clinical } \\
\text { development }\end{array}$ & cIAI & $\begin{array}{l}\text { Likelihood of resistance } \\
\text { among MBL- and } \\
\text { AmpC-co-producing } \\
\text { K. pneumoniae }\end{array}$ \\
\hline Meropenem/nacubactam & $\begin{array}{l}\text { Cell wall } \\
\text { synthesis inhibitor }\end{array}$ & $\begin{array}{l}\text { Under clinical } \\
\text { investigation }\end{array}$ & cIAI & $\begin{array}{l}\text { Occurrence of resistance; } \\
\text { alterations of renal } \\
\text { function }\end{array}$ \\
\hline Plazomicin & Protein synthesis inhibitor & $\begin{array}{l}\text { Yes, FDA-approved in } \\
2018 \text { as ZEMDRI }\end{array}$ & cUTI, BSI, pneumonia & $\begin{array}{l}\text { Ineffective against } \\
\text { MBL-producers }\end{array}$ \\
\hline Eravacycline & Protein synthesis inhibitor & $\begin{array}{l}\text { Yes, FDA-approved in } \\
2018 \text { as XERAVA }\end{array}$ & cIAI, pneumonia & $\begin{array}{l}\text { Not indicated for the } \\
\text { treatment of cUTI }\end{array}$ \\
\hline Cefiderocol & $\begin{array}{c}\text { Cell wall } \\
\text { synthesis inhibitor }\end{array}$ & $\begin{array}{c}\text { Yes, FDA-approved in } \\
2019 \text { as Fetroja }\end{array}$ & cUTI & $\begin{array}{l}\text { Under investigation in } \\
\text { clinical trials }\end{array}$ \\
\hline Omadacycline & Protein synthesis inhibitor & $\begin{array}{l}\text { Yes, FDA-approved in } \\
2018 \text { as NUZYRA }\end{array}$ & cUTI, pneumonia, acute SI & $\begin{array}{l}\text { Limited action against } \\
\text { ESBL-producing } \\
\text { K. pneumoniae }\end{array}$ \\
\hline Delafloxacin & $\begin{array}{c}\text { Protein synthesis inhibitor } \\
\text { (topoisomerase IV and } \\
\text { DNA gyrase) }\end{array}$ & $\begin{array}{c}\text { Yes, FDA-approved in } \\
2017 \text { as Baxdela (USA); } \\
\text { Quofenix (EU). }\end{array}$ & Acute SI, pneumonia & $\begin{array}{l}\text { Peripheral neuropathy } \\
\text { and central nervous } \\
\text { system effects }\end{array}$ \\
\hline
\end{tabular}

${ }^{1}$ cUTI, complicated urinary tract infections; cIAI, complicated intra-abdominal infections; BSI, bloodstream infections; SI, skin infections; PBP, penicillin-binding protein; KPC, Klebsiella pneumoniae carbapenemase.

\section{Future Promising Strategies in CRE Treatment}

The scientific community has focused its efforts on identifying new strategies for combating drug resistance by repositioning non-antibiotic drugs in the antimicrobial arsenal or reconceptualizing old antibiotics.

One of the methodologies in the post-antibiotic era is the use of non-antibiotic drugs for the treatment of multidrug-resistant infections [212]. The benefits are considerable; the details of these drugs' pharmacokinetics and toxicity are already known, and therefore the drugs can be passed directly into phase 2 of clinical trials [213]. However, the costly disadvantage of clinical trials and patent rights remains [214]. Several drugs administered either alone or in conjunction with classical antibiotics have been shown to be effective in removing resistance in CRE, such as antiretroviral compounds (Zidovudine) $[215,216]$, antifungals (Cyclopirox) [217,218], anticancer compounds (Gallium, Mitotane, Tamoxifen) [219-221], and antidepressants (Sertraline) [222]. Many of these even have different therapeutic targets from conventional antibiotics, which act on DNA, the cell wall, or protein translation. Ciclopirox effectively inhibits CRE growth despite its resistant status by interfering with galactose metabolism and LPS (lipopolysaccharides) biosynthesis [217]. Gallium can inhibit ferric redox reactions and associated pathways due to its similarity to iron and can stop the bacterial growth of microorganisms resistant to the last-resort antibiotics [219].

Another promising strategy in the context of antibiotic resistance is the use of ion liquid (IL)-based antimicrobial agents. ILs are generally defined as salts composed solely 
of cations and anions, with melting points below $100{ }^{\circ} \mathrm{C}$, mostly liquid at room temperature [223]. ILs are not new compounds, dating back more than a century, but have raised the awareness of the scientific community due to their tunable biological properties that allow them to be exploited to generate new and unlimited pharmacological combinations with antimicrobial effects [224].

Currently, ILs are categorized in different generations, with the first and secondgeneration IL generally focused on modulation of physicochemical properties and applications. Third-generation ILs (advanced or task-specific ILs) were based on the use of biodegradable and natural ions or ions with known pharmacological activity, such as active pharmaceutical ingredients [225]. The exploitation of ILs is currently of interest for biomedical and pharmaceutical applications. ILs antimicrobial properties fully depend on their structure, which can be adjusted by altering the cationic organic head (positive charge), the tail (usually an alkyl linear chain) and the organic/inorganic or biobased anion [226]. Antimicrobial ILs have several structural and mechanistic characteristics identical to cationic biocides, such as quaternary ammonium compounds (QACs), the primary mode of action of which is membrane-bound protein disruption [227].

The studies have shown that ILs target mainly the cytoplasmic (inner) bacterial membrane [228], which produce changes in the structural and dynamic properties of the outer layers [229] and subsequent disruption and loss of membrane integrity. The general mechanism of action is based on the negative charge of most bacterial cells and on the positive charge of antimicrobial ILs [230]. Consequently, in the first stage of antimicrobial action, there is an interaction between the cationic head group of ILs and the negative structural proteins of the bacterial outer layers [231]. Then, cations are absorbed into the cell layers, connecting to the cytoplasmatic membrane, and penetrating the interior of the cell [232]. ILs further lead to the coagulation of cytoplasmic constituents, causing the inhibition of crucial enzymes (i.e., AMP deaminase, acylase I, cytochrome c oxidase, glutathione reductase acetylcholinesterase, carboxylesterase, catalase), interfering with energy or self-repair processes [233], and finally causing cell death.

Generally, ILs display antimicrobial activity toward a range of bacteria including Gram-positive cocci such as Staphylococcus and Streptococcus, Gram-positive bacteria, including Lactobacillus and Bacillus subtilis, as well as mycobacteria and fungi [229]. The most common IL cationic head groups include imidazolium, pyridinium, quinolinium, morpholinium, pyrrolidinium, and choline ions [224]. The most effective antimicrobial effects have been reported for ILs containing alkyl chains with 10-16 carbon atoms and also showing a balance between hydrophilicity and lipophilicity [234]. The use of amino acids (e.g., proline, tryptophan, phenylalanine, methionine, and valine) as anions is another approach of potential interest [224]. ILs with imidazolium cations and tryptophan anions demonstrated potent antibacterial activity against both Gram-negative and Gram-positive bacteria [235]. Ferraz et al. reported that the administration of ampicillin-based ILs inhibited the bacterial growth of several drug-resistant Gram-negative species (E. coli, Klebsiella pneumoniae), as well as Gram-positive strains of Staphylococcus aureus and Enterococcus faecalis, being superior to sodium ampicillin and bromide and chloride salts. Additionally, the administration of ILs led to the reduction in MIC (minimum inhibitory concentration) for two Gram-negative antibiotic-resistant $E$. coli strains harboring TEM and CTX M9 and CTX M2, respectively, demonstrating the potency of these ampicillin-based ILs for fighting Gram-negative resistant bugs [236]. Other studies have shown the effectiveness of combining organic cations such as choline, alkylammonium, alkyl-pyridiniums, and alkyl-imidazoliums with various inorganic anions or antibiotics (ampicillinate, carbenicillinate, oxacillinate and cephalothinate or penicillin hydrolyzate, and amoxicillin hydrolyzate) in combating the problem of antibiotic resistance in various Enterobacteriaceae strains [236-239]. ILs can also be combined with phage therapy or lysine therapy to strengthen the therapeutic arsenal in the context of antibiotic resistance [240].

Recently, Liu et al. reported syntheses of novel lignin-derived ionic liquids, with extended $\mathrm{N}$-alkyl chains, and examined their melting points, cellulose dissolution capaci- 
ties, and toxicity profiles against Daphnia magna and E. coli. New synthetic approaches to lignin-derive quaternary ammonium compounds (QAC) provided room-temperature ILs that demonstrated rapid cellulose dissolution capacity at $100{ }^{\circ} \mathrm{C}$. The analysis of this compound confirmed that cellulose dissolution also reduced cellulose crystallinity. Broth dilution assays with ILs and E. coli suggested that antibacterial activity was due to both the structure of cations and type of anions. Anion toxicity followed the trend of methane-sulfonate $<$ acetate $<$ hydroxide. In contrast to ILs derived from syringaldehyde and 4-methoxybenzaldehyde, asymmetric methoxy substitution on the benzyl ring of the cation may have reduced the toxicity of vanillin-derived ILs [241]. The antibacterial mechanism of action for ILs is the disruption of the lipopolysaccharide cell membrane, as evidenced by the trend of increasing toxicity with increasing cation $\mathrm{N}$-alkyl chain length

Important attention is also given to poly-ionic liquids (PILs), which can be designated to achieve amphiphilicity, thereby allowing the polymer's rapid and efficient transfer through the lipid bilayer of the bacterial membrane [242]. It has been documented that PILs with high cation density and long alkyl chains have superior antimicrobial efficacy to their small-molecule counterparts [243]. However, the use of PILs is currently limited by bioaccumulation in the environment, and studies are focused on identifying compounds with optimal biodegradability [242].

Testing drugs in clinical trials to investigate their ability to kill bacteria in ways other than conventional methods is extremely laborious and expensive, and most of the time, the results are modest. Thus, the development of new methodologies that reduce costs and increase the discovery of new antibiotics is essential to reinvigorate the antibiotic pipeline. Machine learning approaches can address many of these issues associated with the synthesis, identification, and clinical validation of new compounds with antibiotic properties $[244,245]$. A pioneering deep-learning approach has identified new antibiotics from a pool of more than 107 million molecules, also known as the ZINC15 database. Remarkably, one of these compounds, halicin, is structurally divergent from conventional antibiotics and is potent over a wide range of microorganisms, including Mycobacterium tuberculosis and CRE. Halicin efficiency on pan-resistant $A$. baumannii was also confirmed by in vivo studies. This study highlighted the pivotal role of artificial intelligence approaches in describing and predicting potential candidates' properties in reversing antibiotic resistance [246]. Additionally, some studies have highlighted the role of machine learning approaches in optimizing antibiotic combinations to reverse carbapenem resistance in Gram-negative organisms such as A. baumannii [247]. In a recent study, Chapman et al. combined the UV-visible spectroscopy (UV-Vis) routinely used in microbiology with principal component analysis. In this study, the full potential of UV-Vis spectrophotometry (multiwavelength collection) was used to examine bacterial growth phases when treated with antibiotics and to observe the point of resistance when an antibiotic is introduced into the media, and therefore understand the biochemical changes of the infectious pathogens. Due to the unique experimental setup and procedure that involves indirect use of antibiotics, the same test could be used for obtaining practical information on the type, resistance, and dose of antibiotic necessary to establish the optimum diagnosis and treatment for pathogenic and antibiotic resistant species [248]. In another recent study, Parvaiz et al. exploited the strategy of combination therapeutics, aiming at identifying novel $\beta$-lactamase inhibitors that can inactivate the $\beta$-lactamase enzyme of the pathogen. Inhibitor discovery applied the Site-Identification by Ligand Competitive Saturation (SILCS) technology to map the functional group requirements of the $\beta$-lactamase CMY-10 and generate pharmacophore models of active site. The authors identified certain non- $\beta$-lactam-based $\beta$-lactamase inhibitors that have the potential to be used in combination therapy with lactam-based antibiotics against MDR clinical isolates that have been found resistant against last-line antibiotics [249].

Another strategy exploited to reverse antibiotic resistance comes from synthetic biology, and involves redesigning existing antibiotics to overcome natural resistance mechanisms [250,251]. The concept is based on developing a "LEGO" set of molecular pieces that can be altered and joined together to generate larger molecules with improved antibiotic 
capabilities. This has been demonstrated with a new class of drugs called streptogramins, which block bacterial growth by interfering with protein synthesis. In this regard, Li et al. built new streptogramins from scratch, creating a series of modules that can be modified as needed to generate a series of variations in the structure of streptogramin molecules. After modifying and assembling these molecular LEGO pieces, it was observed that these variations had antimicrobial activity against a wide range of pathogens, including streptogramin-resistant $S$. aureus. Therefore, the synthesis and assembly of slightly modified modules can revitalize several antibiotics classes that have been abandoned due to the natural mechanisms of bacterial resistance, offering new hopes in the war against CRE [252]. Another LEGO-like approach is expected to revitalize endolysins, enzymes employed by bacteriophages to produce cell lysis and virion release, and currently used in the therapeutic management of Gram-negative bacteria [253].

The emergence and spread of Enterobacteriaceae, including CPE, is a significant concern. Therefore, infection control and prevention strategies are crucial for blocking the spread of MDR bacteria. These bacteria possess enzymes that hydrolyze most $\beta$-lactam and other antibiotics, leading to potentially untreatable infections [254]. Generally, transmission occurs rapidly through human and animal populations and hospitals through delayed recognition and breakdowns in infection control. Dissemination is increased by the evolution of 'high-risk clones', characterized by high rates of colonization, invasive disease, and transmissibility in healthcare settings. Person-to-person transmission through healthcare workers is considered the main route of transmission; however, the role of the environment in multidrug-resistant bacteria transmission is increasingly recognized [255]. CPE and those harboring ESBL can survive in biofilms within hospital drains, toilets, equipment, and other environmental niches that are difficult to access and clean. Consequently, engineering solutions, including toilet, sink, or drain removal, are necessary [256]. When CPE is recognized, environmental control should be intensified, patient surroundings should be disinfected and cleaned daily, specialized equipment should be used, and unnecessary transfers avoided.

The correlation between hand hygiene and the prevention of the spread of disease was established in 1847 when Ignaz Semmelweis documented evidence to demonstrate the effect of hand hygiene in preventing nosocomial infections [257]. The studies show that various hand hygiene methods reduce bacterial load significantly and prevent crosstransmission and health care associated infections $[258,259]$. The role of hand hygiene is to prevent colonization and infection in the patient and environmental contamination. The need for hand hygiene arises whenever a microorganism transfers from one skin or inanimate surface to another surface [258]. First Global Patient Safety Challenge "Clean Care is Safer Care" (CCiSC) recommends a "five moments" approach, considered critical for meeting the needs for training, compliance measurements, and comparable performance reporting [260]. This "five moments" concept consists of a complex sequence of care which can be summarized as follows: (1) Before touching a patient; (2) Before a clean/aseptic procedure; (3) After exposure to a body fluid; (4) After touching a patient; and (5) After touching patient surroundings. The detailed recommendations can be found in the WHO Guidelines on Hand Hygiene in Health Care and the original publication [260].

In infection control and prevention strategies, antimicrobial stewardship (AMS) has a critical role. AMS deals with optimizing antimicrobial use, including dose, route, and duration, and the reduction of unnecessary use [261]. Given that up to $50 \%$ of antibiotic usage is either unnecessary or inappropriate [262], the proper administration of antibiotics is a critical factor in tackling antibiotic resistance. Prescribing the correct antibiotic at the right time and for the proper diagnosis is essential for the success of AMS strategies [261].

\section{Discussion}

According to the Global Priority List published by the WHO, CRE poses an exponentially growing threat to global public health. These pathogens have diverse and versatile mechanisms of antibiotic resistance, which complicate the clinical management of asso- 
ciated infections; however, the presence and diversification of $\beta$-lactamases remain the most problematic mechanism [263]. Briefly, there are at least three main groups of enzymes that mediate carbapenem resistance in Enterobacteriaceae, as follows: KPC (Ambler class A), MBLs (Ambler class B), and OXA-48-like (Ambler class D) $\beta$-lactamases [264]. In the USA, studies reported an increased prevalence of existing KPC and OXA-48-like producing Enterobacteriaceae strains; in contrast, Ambler class B enzymes are endemic in Europe [265]. Therefore, a concentration of the medical and scientific community's efforts is needed to control the infections as effectively as possible and prevent the acquisition of resistance. Considering that several resistance mechanisms may coexist in Enterobacteriaceae strains, more specific approaches to these problematic infections are necessary. These strategies may involve either repurposing certain compounds and antibiotics, dual therapies with antibiotics, or reinvigorating the antibiotic pipeline with novel BLIs and antibiotics [263]. The most effective therapeutic strategy for the treatment of infections caused by CRE is still controversial. However, the scientific community's recommendations suggest that the ideal therapy for resistant Gram-negative pathogens, including CRE, should be delivered, taking into account the mechanisms of resistance, $\beta$-lactamases present, susceptibility profiles of resistant organisms, and the severity of the patient's illness [143,265].

Particular attention is currently being paid to new antibiotics such as CAZ/AVI, AZT/AVI, MER/VAB, plazomicin, and cefiderocol. Based on clinical data available to date, CAZ/AVI, MER/VAB, and IMI/REL are the preferred therapies for KPC-producing Enterobacterales due to their remarkable stability [265]. CASE/AVI is one of the most widely used therapies in the clinical management of CRE. CAZ/AVI received FDA approval in 2015 and is recommended for the treatment of a wide range of Gram-negative infections, including cUTI, complicated intra-abdominally infections (cIAI), BSI, pneumonia, as well as hospital-associated and ventilator-associated pneumonia (PAH/VAP) [100-102]. The effectiveness of this combination is based on the addition of AVI, which is a non- $\beta$ lactam- $\beta$-lactamase inhibitor that reinforces the activity of ceftazidime on class A (KPCs) and $C(A m p C) \beta$-lactamases, as well as certain class D enzymes (OXA48) [29]. In surveillance studies, CAZ/AVI is superior to traditional antibiotics used (e.g., carbapenem and an aminoglycoside; carbapenem plus colistin) in the management of CR K. pneumoniae isolates [105]. This combination showed an excellent safety profile and was associated with a slight improvement in the mortality rate in CRE patients from $32 \%$ associated with colistin use to $9 \%[105,106]$. However, the enthusiasm generated by these studies is tempered by the observations according to which resistance to CAZ/AVI often occurs in CRE isolates, involving either the production of MBLs [104], mutations in different KPC enzymes [107,108], decreased outer membrane permeability, or enhanced drug efflux [109]. Therefore, all this information suggests the need to use the CAZ/AVI combination with caution in managing CRE infections.

IMI/REL gained FDA approval in July 2019, whereas MER/VAB was approved for use in the USA in 2017 [266]. Interestingly, it has been observed that adding REL, an AVIlike BLI, to IMI can increase the susceptibility of CRE isolates from $8 \%$ to $88 \%$ to IMI [120]. In general, IMI/REL has good activity on class A and class C $\beta$-lactamases. However, information on CRE susceptibility levels to IMI/REL remains conflicting. For example, a study conducted by Livermore et al. demonstrated a modest efficacy of IMI/REL on K. pneumoniae VIM, IMP, and NDM-producing strains [123]; in contrast, two other independent studies reported a 100\% susceptibility on KPC-2 and KPC-3-producing K. pneumoniae isolates [120,124]. IMI/REL also proved its potency against CAZ/AVI-resistant K. pneumoniae isolates that harbored OXA-48-type carbapenemase. This study highlighted that IMI/REL and CAZ/AVI have overlapping spectra of action. These therapies can be used in conjunction to improve the therapeutic management of CRE infections [120]. Similarly, MER/VAB combination's efficacy and safety were tested in two clinical trials, TANGO I and TANGO II, showing results as good as for other compounds and antibacterial combinations used in managing CRE infections [128,129]. MER/VAB also has a pronounced activity on class A and class $C \beta$-lactamases. Recently, MER/ VAB has gained approval from the European 
Medicines Agency (EMA) to treat cUTI, acute pyelonephritis, cIAIs, HAP, VAP, and other infections caused by aerobic Gram-negative pathogens in adults with limited treatment options [130]. Although well analyzed in clinical trials, many more studies are needed on the long-term stability of MER/VAB and IMI/REL and on the potential for antimicrobial resistance, as reported in the case of abusive administration of CAZ/AVI [265].

Plazomicin (Achaogen) is a next-generation semisynthetic aminoglycoside acting against bacteria producing AMEs [161]. In contrast with other aminoglycosides, several studies report higher potency of plazomicin against KPC-producing Enterobacteriaceae [267]. For instance, one of these studies investigated collections of clinically relevant KPC-producers with resistance to aminoglycosides and observed inhibition using plazomicin, with an MIC90 value of $\leq 2 \mathrm{mg} / \mathrm{L}$ [169]. Despite these promising results, MBL-producers are resistant to this antibiotic due to the methyltransferase enzymes commonly found, especially in NDM-producers [169]. Although aminoglycosides are not generally used as monotherapy, the broad spectrum of activity and low renal toxicity of plazomicin make it a choice for a targeted monotherapy against extensively-drug resistant Enterobacteriaceae causing UTI [173].

Another recently approved antibiotic in the fight against CRE is cefiderocol, also known as S-649266 [143]. According to the latest data, cefiderocol has been noted as one of the most potent antimicrobial compounds in the fight against fermenting and non-fermenting Gram-negative pathogens, including CRE [144]. Cefiderocol differs from all the agents mentioned above in that it provides activity against all four classes of $\beta$-lactamases [265]. In the ARGONAUT-I study, cefiderocol demonstrated in vitro superior antibacterial activity to the comparator drugs (e.g., cefepime, aztreonam, ceftazidime, CAZ/AVI, and CEF/TAZ) in combating CRE infections [268]. Additionally, in this study, it was observed that the type of the carbapenemase expressed by CRE influenced the activity of cefiderocol with MICs of $1 \mathrm{mg} / \mathrm{L}$ for strains expressing OXA-48-like genes, $2 \mathrm{mg} / \mathrm{L}$ for KPC-3, and $8 \mathrm{mg} / \mathrm{L}$ for strains producing NDM, KPC-2, and ESBLs [268]. Moreover, Karlowsky et al. showed that at a concentration of $\leq 4 \mathrm{mg} / \mathrm{L}$, cefiderocol possesses in vitro activity against over 99\% of Enterobacteriaceae strains resistant to CAZ/AVI ceftolozane/tazobactam, cefepime, ciprofloxacin, and colistin [147]. Despite the promising in vitro results of cefiderocol, the expected role in clinical practice is unclear due to the findings of higher all-cause mortality compared to the best available therapy for managing life-threatening infections caused by CRE [150]. In contrast with the presented agents, cefiderocol remains the only agent with activity against class B enzymes and may have a role in treating these infections. However, additional active agents are currently in the pipeline, including aztreonam combinations such as AZT/AVI [265].

AZT / AVI is a particular compound combining two FDA-approved agents: AZT and CAZ/AVI, that exerts activity on CPE and MBLs [153]. AZT is mainly resistant to the action of MBLs; however, aztreonam can be readily hydrolyzed by Ambler class A or class C $\beta$-lactamases [152]. Notably, avibactam can inhibit these secondary $\beta$-lactamases, which is why the AZT-AVI combination may be a valuable therapeutic strategy against $\mathrm{M} \beta \mathrm{L}$-producing organisms with secondary $\beta$-lactamases [153]. Case reports describe successful combinations of aztreonam, including CAZ-AVI, in the management of CRE infections. In a collection of 70 aztreonam non-susceptible CPE isolates, the addition of AVI restored their sensitivity to AZT [152]. Overall, for the entire collection of 70 isolates, the combined MIC90s were $>64 \mathrm{mg} / \mathrm{L}$ for aztreonam and $2 \mathrm{mg} / \mathrm{L}$ for AZT/AVI combinations, this dose of AZT/AVI formulation blocking bacterial growth for approximately $98.6 \%$ of CRE strains [152]. Moreover, another study aiming to analyze the in vitro activity of CAZ-AVI and AZT/AVI, respectively, on CP-CRE and non-CP-CRE strains reported that CAZ/AVI was more potent against CRE isolates than AZT/AVI [155]. However, when compared to CAZ/AVI, AZT/AVI was less potent against non-CP-CRE isolates. The inoculum effect was much more prominent with AZT/AVI than in CAZ/AVI (47\% and $18 \%$, respectively), especially in K. pneumoniae isolates. Therefore, the use of the AZT/AVI combination should be performed with caution in the clinical context since the presence 
of a substantial inoculum effect may contribute to the clinical failure of high-inoculum infections treated with AZT/AVI [155].

Eravacycline, omadacycline and delafloxacin are new synthetic agents recently approved by the FDA and commercially available for treating infections caused by MDR microorganisms, acute bacterial skin and skin structure infections and community-acquired bacterial pneumonia. These agents demonstrated greater in vitro and in vivo potency and a clinical efficacy high as that of the comparator drugs (e.g., vancomycin, moxifloxacin, ceftriaxone, linezolid, levofloxacin) $[183,188,189,203]$.

\section{Conclusions}

BLAs remain at present one of the most efficient antibiotic classes against MDR pathogens. Third generation penicillins (aminopenicillins, carboxypenicillins), the fifth generation of cephalosporins, and newly added cefiderococol are the most effective BLAs against MDR Gram-negative bacteria. The discovery of novel antibiotics, counteracting antimicrobial resistance through BLIs, is a promising strategy that could amplify these antibiotics' action against CPE. Clinical trials have also revealed that CAZ-AVI, IMI-REL, and MEM-VAB are some of the most potent formulations in the fight against MDR-CPE. However, further studies in establishing new potent inhibitor formulations and their validation in clinical trials are required.

Future perspectives such as non-antibiotic drugs administered alone or in conjunction with classical antibiotics can be efficient in the fight against antimicrobial resistance. Other promising strategies exploited to reverse antibiotic resistance comes from liquid ion-based antimicrobial agents (ILs), machine learning approaches, and synthetic biology. More research is needed to find compounds with optimal biodegradability and efficient approaches to redesign antibiotic molecules in order to overcome antimicrobial resistance.

In the case of patients harboring CRE infections, physicians are undoubtedly left in a challenging situation: either they continue treating patients with older drugs with well-known drawbacks, or they adopt the new antibiotics, despite their higher costs and insufficient evidence of effect against CRE. A fine balance between these two treatment options is most likely to be the current best strategy. Despite that, more significant efforts must be devoted to designing and performing randomized clinical trials for CRE treatment.

Author Contributions: M.C.C. conceived the manuscript; C.O.V., E.G.D. and R.E.C. drafted the manuscript; I.G., I.B., and M.C.C. revised the manuscript. All authors have read and agreed to the published version of the manuscript.

Funding: This study was supported by the Romanian Executive Agency for Higher Education, Research, Development and Innovation, research projects PN-III-P4-ID-PCCF-2016-0114 POSCCE (RADAR), PN-III-P1-1.1-PD-2016-1798 (PD-148), and PN-III-P1-1.1-PD-2016-2137. The authors declare that they have no known competing financial interests or personal relationships that could have appeared to influence the work reported in this paper.

Conflicts of Interest: The authors declare no conflict of interest.

\section{References}

1. Wolrd Health Organization. WHO Priority Pathogens List for RED of New Antibiotics; WHO: Geneva, Switzerland, 2017.

2. Lee, C.-M.; Lai, C.-C.; Chiang, H.-T.; Lu, M.-C.; Wang, L.-F.; Tsai, T.-L.; Kang, M.-Y.; Jan, Y.-N.; Lo, Y.-T.; Ko, W.-C.; et al. Presence of multidrug-resistant organisms in the residents and environments of long-term care facilities in Taiwan. J. Microbiol. Immunol. Infect. 2017, 50, 133-144. [CrossRef] [PubMed]

3. D'Angelo, R.G.; Johnson, J.K.; Bork, J.T.; Heil, E.L. Treatment options for extended-spectrum beta-lactamase (ESBL) and AmpCproducing bacteria. Expert Opin. Pharmacother. 2016, 17, 953-967. [CrossRef]

4. Ambler, R.P. The structure of beta-lactamases. Philos. Trans. R. Soc. Lond. Ser. B Biol. Sci. 1980, 289, 321-331. [CrossRef]

5. Yigit, H.; Queenan, A.M.; Anderson, G.J.; Domenech-Sanchez, A.; Biddle, J.W.; Steward, C.D.; Alberti, S.; Bush, K.; Tenover, F.C. Novel carbapenem-hydrolyzing beta-lactamase, KPC-1, from a carbapenem-resistant strain of Klebsiella pneumoniae. Antimicrob. Agents Chemother. 2001, 45, 1151-1161. [CrossRef]

6. Codjoe, F.S.; Donkor, E.S. Carbapenem Resistance: A Review. Med. Sci. 2017, 6, 1. [CrossRef] 
7. Logan, L.K.; Weinstein, R.A. The Epidemiology of Carbapenem-Resistant Enterobacteriaceae: The Impact and Evolution of a Global Menace. J. Infect. Dis. 2017, 215, S28-S36. [CrossRef]

8. Tzouvelekis, L.S.; Markogiannakis, A.; Psichogiou, M.; Tassios, P.T.; Daikos, G.L. Carbapenemases in Klebsiella pneumoniae and other Enterobacteriaceae: An evolving crisis of global dimensions. Clin. Microbiol. Rev. 2012, 25, 682-707. [CrossRef] [PubMed]

9. Centers for Disease Control and Prevention. National Action Plan for Combating Antibiotic-resistant Bacteria; CDC: Atlanta, GA, USA, 2015.

10. Infectious Disease Society of America. The $10 \times$ '20 Initiative: Pursuing a global commitment to develop 10 new antibacterial drugs by 2020. Clin. Infect. Dis. 2010, 50, 1081-1083. [CrossRef]

11. Nikaido, H.; Pagès, J.-M. Broad-specificity efflux pumps and their role in multidrug resistance of Gram-negative bacteria. FEMS Microbiol. Rev. 2012, 36, 340-363. [CrossRef]

12. Masi, M.; Réfregiers, M.; Pos, K.M.; Pagès, J.-M. Mechanisms of envelope permeability and antibiotic influx and efflux in Gram-negative bacteria. Nat. Microbiol. 2017, 2, 17001. [CrossRef] [PubMed]

13. Vergalli, J.; Bodrenko, I.V.; Masi, M.; Moynié, L.; Acosta-Gutiérrez, S.; Naismith, J.H.; Davin-Regli, A.; Ceccarelli, M.; van den Berg, B.; Winterhalter, M.; et al. Porins and small-molecule translocation across the outer membrane of Gram-negative bacteria. Nat. Rev. Microbiol. 2020, 18, 164-176. [CrossRef] [PubMed]

14. Lee, J.-Y.; Hong, Y.-K.; Lee, H.; Ko, K.S. High prevalence of non-clonal imipenem-nonsusceptible Enterobacter spp. isolates in Korea and their association with porin down-regulation. Diagn. Microbiol. Infect. Dis. 2017, 87, 53-59. [CrossRef] [PubMed]

15. Ye, Y.; Xu, L.; Han, Y.; Chen, Z.; Liu, C.; Ming, L. Mechanism for carbapenem resistance of clinical Enterobacteriaceae isolates. Exp. Ther. Med. 2018, 15, 1143-1149. [CrossRef] [PubMed]

16. Lomovskaya, O.; Sun, D.; Rubio-Aparicio, D.; Nelson, K.; Tsivkovski, R.; Griffith, D.C.; Dudley, M.N. Vaborbactam: Spectrum of Beta-Lactamase Inhibition and Impact of Resistance Mechanisms on Activity in Enterobacteriaceae. Antimicrob. Agents Chemother. 2017, 61. [CrossRef] [PubMed]

17. Wilson, W.R.; Kline, E.G.; Jones, C.E.; Morder, K.T.; Mettus, R.T.; Doi, Y.; Nguyen, M.H.; Clancy, C.J.; Shields, R.K. Effects of KPC Variant and Porin Genotype on the In Vitro Activity of Meropenem-Vaborbactam against Carbapenem-Resistant Enterobacteriaceae. Antimicrob. Agents Chemother. 2019, 63, e02048-18. [CrossRef]

18. Miao, M.; Wen, H.; Xu, P.; Niu, S.; Lv, J.; Xie, X.; Mediavilla, J.R.; Tang, Y.-W.; Kreiswirth, B.N.; Zhang, X.; et al. Genetic Diversity of Carbapenem-Resistant Enterobacteriaceae (CRE) Clinical Isolates from a Tertiary Hospital in Eastern China. Front. Microbiol. 2018, 9, 3341. [CrossRef]

19. D’Onofrio, V.; Conzemius, R.; Varda-Brkić, D.; Bogdan, M.; Grisold, A.; Gyssens, I.C.; Bedenić, B.; Barišić, I. Epidemiology of colistin-resistant, carbapenemase-producing Enterobacteriaceae and Acinetobacter baumannii in Croatia. Infect. Genet. Evol. J. Mol. Epidemiol. Evol. Genet. Infect. Dis. 2020, 81, 104263. [CrossRef] [PubMed]

20. Nang, S.C.; Li, J.; Velkov, T. The rise and spread of mcr plasmid-mediated polymyxin resistance. Crit. Rev. Microbiol. 2019, 45, 131-161. [CrossRef] [PubMed]

21. Macesic, N.; Nelson, B.; Mcconville, T.H.; Giddins, M.J.; Green, D.A.; Stump, S.; Gomez-Simmonds, A.; Annavajhala, M.K.; Uhlemann, A.-C. Emergence of Polymyxin Resistance in Clinical Klebsiella pneumoniae Through Diverse Genetic Adaptations: A Genomic, Retrospective Cohort Study. Clin. Infect. Dis. 2020, 70, 2084-2091. [CrossRef]

22. De Araújo Longo, L.G.; Fontana, H.; Santos de Sousa, V.; Chilinque Zambão da Silva, N.; Souto Martins, I.; Meurer Moreira, B. Emergence of mgrB locus deletion mediating polymyxin resistance in pandemic KPC-producing Klebsiella pneumoniae ST15 lineage. J. Med. Microbiol. 2021. [CrossRef] [PubMed]

23. Fu, Y.; Chen, Y.; Liu, D.; Yang, D.; Liu, Z.; Wang, Y.; Wang, J.; Wang, X.; Xu, X.; Li, X.; et al. Abundance of tigecycline resistance genes and association with antibiotic residues in Chinese livestock farms. J. Hazard. Mater. 2021, 409, 124921. [CrossRef] [PubMed]

24. Xu, J.; Zhu, Z.; Chen, Y.; Wang, W.; He, F. The Plasmid-Borne tet(A) Gene Is an Important Factor Causing Tigecycline Resistance in ST11 Carbapenem-Resistant Klebsiella pneumoniae Under Selective Pressure. Front. Microbiol. 2021, 12, 644949. [CrossRef] [PubMed]

25. Ugah, U.I.; Udeani, T.K. High Prevalence of Phenotypic Resistance to Colistin, Tigecycline and Netilmicin in a Region with no History of Colistin Administration in Nigeria. Clin. Lab. 2021, 67. [CrossRef] [PubMed]

26. Rodríguez-Baño, J.; Gutiérrez-Gutiérrez, B.; Machuca, I.; Pascual, A. Treatment of Infections Caused by Extended-Spectrum-BetaLactamase-, AmpC-, and Carbapenemase-Producing Enterobacteriaceae. Clin. Microbiol. Rev. 2018, 31. [CrossRef] [PubMed]

27. Falagas, M.E.; Karageorgopoulos, D.E.; Nordmann, P. Therapeutic options for infections with Enterobacteriaceae producing carbapenem-hydrolyzing enzymes. Future Microbiol. 2011, 6, 653-666. [CrossRef]

28. Livermore, D.M.; Warner, M.; Mushtaq, S.; Doumith, M.; Zhang, J.; Woodford, N. What remains against carbapenem-resistant Enterobacteriaceae? Evaluation of chloramphenicol, ciprofloxacin, colistin, fosfomycin, minocycline, nitrofurantoin, temocillin and tigecycline. Int. J. Antimicrob. Agents 2011, 37, 415-419. [CrossRef]

29. Karaiskos, I.; Lagou, S.; Pontikis, K.; Rapti, V.; Poulakou, G. The "Old" and the "New" Antibiotics for MDR Gram-Negative Pathogens: For Whom, When, and How. Front. Public Health 2019, 7, 151. [CrossRef]

30. Falagas, M.E.; Rafailidis, P.I.; Kasiakou, S.K.; Hatzopoulou, P.; Michalopoulos, A. Effectiveness and nephrotoxicity of colistin monotherapy vs. colistin-meropenem combination therapy for multidrug-resistant Gram-negative bacterial infections. Clin. Microbiol. Infect. Dis. 2006, 12, 1227-1230. [CrossRef]

31. Pogue, J.M.; Lee, J.; Marchaim, D.; Yee, V.; Zhao, J.J.; Chopra, T.; Lephart, P.; Kaye, K.S. Incidence of and risk factors for colistin-associated nephrotoxicity in a large academic health system. Clin. Infect. Dis. 2011, 53, 879-884. [CrossRef] 
32. Martis, N.; Leroy, S.; Blanc, V. Colistin in multi-drug resistant Pseudomonas aeruginosa blood-stream infections: A narrative review for the clinician. J. Infect. 2014, 69, 1-12. [CrossRef]

33. Grégoire, N.; Aranzana-Climent, V.; Magréault, S.; Marchand, S.; Couet, W. Clinical Pharmacokinetics and Pharmacodynamics of Colistin. Clin. Pharmacokinet. 2017, 56, 1441-1460. [CrossRef]

34. Kazmierczak, K.M.; de Jonge, B.L.M.; Stone, G.G.; Sahm, D.F. In vitro activity of ceftazidime/avibactam against isolates of Enterobacteriaceae collected in European countries: INFORM global surveillance 2012-15. J. Antimicrob. Chemother. 2018, 73, 2782-2788. [CrossRef] [PubMed]

35. Karaiskos, I.; Souli, M.; Galani, I.; Giamarellou, H. Colistin: Still a lifesaver for the 21st century? Expert Opin. Drug Metab. Toxicol. 2017, 13, 59-71. [CrossRef] [PubMed]

36. Karaiskos, I.; Antoniadou, A.; Giamarellou, H. Combination therapy for extensively-drug resistant gram-negative bacteria. Expert Rev. Anti. Infect. Ther. 2017, 15, 1123-1140. [CrossRef] [PubMed]

37. Daikos, G.L.; Tsaousi, S.; Tzouvelekis, L.S.; Anyfantis, I.; Psichogiou, M.; Argyropoulou, A.; Stefanou, I.; Sypsa, V.; Miriagou, V.; Nepka, M.; et al. Carbapenemase-producing Klebsiella pneumoniae bloodstream infections: Lowering mortality by antibiotic combination schemes and the role of carbapenems. Antimicrob. Agents Chemother. 2014, 58, 2322-2328. [CrossRef] [PubMed]

38. Tsuji, B.T.; Pogue, J.M.; Zavascki, A.P.; Paul, M.; Daikos, G.L.; Forrest, A.; Giacobbe, D.R.; Viscoli, C.; Giamarellou, H.; Karaiskos, I.; et al. International Consensus Guidelines for the Optimal Use of the Polymyxins: Endorsed by the American College of Clinical Pharmacy (ACCP), European Society of Clinical Microbiology and Infectious Diseases (ESCMID), Infectious Diseases Society of America (IDSA), International Society for Anti-infective Pharmacology (ISAP), Society of Critical Care Medicine (SCCM), and Society of Infectious Diseases Pharmacists (SIDP). Pharmacotherapy 2019, 39, 10-39. [CrossRef]

39. Liu, Y.-Y.; Wang, Y.; Walsh, T.R.; Yi, L.-X.; Zhang, R.; Spencer, J.; Doi, Y.; Tian, G.; Dong, B.; Huang, X.; et al. Emergence of plasmid-mediated colistin resistance mechanism MCR-1 in animals and human beings in China: A microbiological and molecular biological study. Lancet Infect. Dis. 2016, 16, 161-168. [CrossRef]

40. Izdebski, R.; Baraniak, A.; Bojarska, K.; Urbanowicz, P.; Fiett, J.; Pomorska-Wesołowska, M.; Hryniewicz, W.; Gniadkowski, M.; Żabicka, D. Mobile MCR-1-associated resistance to colistin in Poland. J. Antimicrob. Chemother. 2016, 71, 2331-2333. [CrossRef]

41. Baron, S.; Hadjadj, L.; Rolain, J.-M.; Olaitan, A.O. Molecular mechanisms of polymyxin resistance: Knowns and unknowns. Int. J. Antimicrob. Agents 2016, 48, 583-591. [CrossRef]

42. Zhang, H.; Zhao, D.; Quan, J.; Hua, X.; Yu, Y. mcr-1 facilitated selection of high-level colistin-resistant mutants in Escherichia coli. Clin. Microbiol. Infect. 2019, 25, 517.e1-517.e4. [CrossRef]

43. Xavier, B.B.; Lammens, C.; Ruhal, R.; Kumar-Singh, S.; Butaye, P.; Goossens, H.; Malhotra-Kumar, S. Identification of a novel plasmid-mediated colistin-resistance gene, mcr-2, in Escherichia coli, Belgium, June 2016. Euro Surveill. 2016, 21 , 30280. [CrossRef] [PubMed]

44. Yin, W.; Li, H.; Shen, Y.; Liu, Z.; Wang, S.; Shen, Z.; Zhang, R.; Walsh, T.R.; Shen, J.; Wang, Y. Novel Plasmid-Mediated Colistin Resistance Gene mcr-3 in Escherichia coli. MBio 2017, 8, e00543-17. [CrossRef] [PubMed]

45. Carattoli, A.; Villa, L.; Feudi, C.; Curcio, L.; Orsini, S.; Luppi, A.; Pezzotti, G.; Magistrali, C.F. Novel plasmid-mediated colistin resistance mcr-4 gene in Salmonella and Escherichia coli, Italy 2013, Spain and Belgium, 2015 to 2016. Euro Surveill. 2017, 22, 30589. [CrossRef] [PubMed]

46. Borowiak, M.; Fischer, J.; Hammerl, J.A.; Hendriksen, R.S.; Szabo, I.; Malorny, B. Identification of a novel transposon-associated phosphoethanolamine transferase gene, mcr-5, conferring colistin resistance in d-tartrate fermenting Salmonella enterica subsp. enterica serovar Paratyphi B. J. Antimicrob. Chemother. 2017, 72, 3317-3324. [CrossRef] [PubMed]

47. Carroll, L.M.; Gaballa, A.; Guldimann, C.; Sullivan, G.; Henderson, L.O.; Wiedmann, M. Identification of Novel Mobilized Colistin Resistance Gene mcr-9 in a Multidrug-Resistant, Colistin-Susceptible Salmonella enterica Serotype Typhimurium Isolate. MBio 2019, 10, e00853-19. [CrossRef]

48. Vrancianu, C.O.; Popa, L.I.; Bleotu, C.; Chifiriuc, M.C. Targeting Plasmids to Limit Acquisition and Transmission of Antimicrobial Resistance. Front. Microbiol. 2020, 11, 761. [CrossRef]

49. Berglund, B.; Hoang, N.T.B.; Tärnberg, M.; Le, N.K.; Svartström, O.; Khu, D.T.K.; Nilsson, M.; Le, H.T.; Welander, J.; Olson, L.; et al. Insertion sequence transpositions and point mutations in mgrB causing colistin resistance in a clinical strain of carbapenemresistant Klebsiella pneumoniae from Vietnam. Int. J. Antimicrob. Agents 2018, 51, 789-793. [CrossRef]

50. Uz Zaman, T.; Albladi, M.; Siddique, M.I.; Aljohani, S.M.; Balkhy, H.H. Insertion element mediated mgrB disruption and presence of ISKpn28 in colistin-resistant Klebsiella pneumoniae isolates from Saudi Arabia. Infect. Drug Resist. 2018, 11, 1183-1187. [CrossRef]

51. Snyman, Y.; Whitelaw, A.C.; Reuter, S.; Maloba, M.R.B.; Newton-Foot, M. Colistin Resistance Mechanisms in Clinical Escherichia coli and Klebsiella spp. Isolates from the Western Cape of South Africa. Microb. Drug Resist. 2021. ahead of print. [CrossRef]

52. He, Y.-Z.; Long, T.-F.; He, B.; Li, X.-P.; Li, G.; Chen, L.; Liao, X.-P.; Liu, Y.-H.; Sun, J. ISEc69-Mediated Mobilization of the Colistin Resistance Gene mcr-2 in Escherichia coli. Front. Microbiol. 2020, 11, 564973. [CrossRef]

53. Falagas, M.E.; Vouloumanou, E.K.; Samonis, G.; Vardakas, K.Z. Fosfomycin. Clin. Microbiol. Rev. 2016, 29, 321-347. [CrossRef] [PubMed]

54. Pontikis, K.; Karaiskos, I.; Bastani, S.; Dimopoulos, G.; Kalogirou, M.; Katsiari, M.; Oikonomou, A.; Poulakou, G.; Roilides, E.; Giamarellou, H. Outcomes of critically ill intensive care unit patients treated with fosfomycin for infections due to pandrugresistant and extensively drug-resistant carbapenemase-producing Gram-negative bacteria. Int. J. Antimicrob. Agents 2014, 43, 52-59. [CrossRef] [PubMed] 
55. Monden, K.; Ando, E.; Iida, M.; Kumon, H. Role of fosfomycin in a synergistic combination with ofloxacin against Pseudomonas aeruginosa growing in a biofilm. J. Infect. Chemother. 2002, 8, 218-226. [CrossRef] [PubMed]

56. Popovic, M.; Steinort, D.; Pillai, S.; Joukhadar, C. Fosfomycin: An old, new friend? Clin. Microbiol. Infect. Dis. 2010, 29, 127-142. [CrossRef] [PubMed]

57. Michalopoulos, A.S.; Livaditis, I.G.; Gougoutas, V. The revival of fosfomycin. Int. J. Infect. Dis. 2011, 15, e732-e739. [CrossRef]

58. Clinical and Laboratory Standards Institute. Performance Standards for Antimicrobial Susceptibility Testing; Clinical and Laboratory Standards Institute: Wayne, PA, USA, 2020.

59. Candel, F.J.; Cantón, R. Current approach to fosfomycin: From bench to bedside. Enferm. Infecc. Microbiol. Clin. 2019, 37, 1-3. [CrossRef]

60. Rodríguez-Baño, J.; Cisneros, J.M.; Cobos-Trigueros, N.; Fresco, G.; Navarro-San Francisco, C.; Gudiol, C.; Horcajada, J.P.; López-Cerero, L.; Martínez, J.A.; Molina, J.; et al. Executive summary of the diagnosis and antimicrobial treatment of invasive infections due to multidrug-resistant Enterobacteriaceae. Guidelines of the Spanish Society of Infectious Diseases and Clinical Microbiology (SEIMC). Enferm. Infecc. Microbiol. Clin. 2015, 33, 338-341. [CrossRef]

61. López-Cerero, L.; de Cueto, M.; Díaz-Guerrero, M.A.; Morillo, C.; Pascual, A. Evaluation of the Etest method for fosfomycin susceptibility of ESBL-producing Klebsiella pneumoniae. J. Antimicrob. Chemother. 2007, 59, 810-812. [CrossRef]

62. De Cueto, M.; López, L.; Hernández, J.R.; Morillo, C.; Pascual, A. In vitro activity of fosfomycin against extended-spectrum-betalactamase-producing Escherichia coli and Klebsiella pneumoniae: Comparison of susceptibility testing procedures. Antimicrob. Agents Chemother. 2006, 50, 368-370. [CrossRef]

63. Kaase, M.; Szabados, F.; Anders, A.; Gatermann, S.G. Fosfomycin susceptibility in carbapenem-resistant Enterobacteriaceae from Germany. J. Clin. Microbiol. 2014, 52, 1893-1897. [CrossRef]

64. Ballestero-Téllez, M.; Docobo-Pérez, F.; Rodríguez-Martínez, J.M.; Conejo, M.C.; Ramos-Guelfo, M.S.; Blázquez, J.; Rodríguez-Baño, J.; Pascual, A. Role of inoculum and mutant frequency on fosfomycin MIC discrepancies by agar dilution and broth microdilution methods in Enterobacteriaceae. Clin. Microbiol. Infect. 2017, 23, 325-331. [CrossRef]

65. Aprile, A.; Scalia, G.; Stefani, S.; Mezzatesta, M.L. In vitro fosfomycin study on concordance of susceptibility testing methods against ESBL and carbapenem-resistant Enterobacteriaceae. J. Glob. Antimicrob. Resist. 2020, 23, 286-289. [CrossRef]

66. Campanile, F.; Wootton, M.; Davies, L.; Aprile, A.; Mirabile, A.; Pomponio, S.; Demetrio, F.; Bongiorno, D.; Walsh, T.R.; Stefani, S.; et al. Gold standard susceptibility testing of fosfomycin in Staphylococcus aureus and Enterobacterales using a new agar dilution panel ${ }^{\circledR}$. J. Glob. Antimicrob. Resist. 2020, 23, 334-337. [CrossRef] [PubMed]

67. Cottell, J.L.; Webber, M.A. Experiences in fosfomycin susceptibility testing and resistance mechanism determination in Escherichia coli from urinary tract infections in the UK. J. Med. Microbiol. 2019, 68, 161-168. [CrossRef] [PubMed]

68. Smith, E.C.; Brigman, H.V.; Anderson, J.C.; Emery, C.L.; Bias, T.E.; Bergen, P.J.; Landersdorfer, C.B.; Hirsch, E.B. Performance of Four Fosfomycin Susceptibility Testing Methods against an International Collection of Clinical Pseudomonas aeruginosa Isolates. J. Clin. Microbiol. 2020, 58, e01121-20. [CrossRef] [PubMed]

69. Mojica, M.F.; De La Cadena, E.; Hernández-Gómez, C.; Correa, A.; Appel, T.M.; Pallares, C.J.; Villegas, M.V. Performance of disk diffusion and broth microdilution for fosfomycin susceptibility testing of multidrug-resistant clinical isolates of Enterobacterales and Pseudomonas aeruginosa. J. Glob. Antimicrob. Resist. 2020, 21, 391-395. [CrossRef] [PubMed]

70. Albur, M.S.; Noel, A.; Bowker, K.; MacGowan, A. The combination of colistin and fosfomycin is synergistic against NDM-1producing Enterobacteriaceae in in vitro pharmacokinetic/pharmacodynamic model experiments. Int. J. Antimicrob. Agents 2015, 46, 560-567. [CrossRef]

71. Vardakas, K.Z.; Legakis, N.J.; Triarides, N.; Falagas, M.E. Susceptibility of contemporary isolates to fosfomycin: A systematic review of the literature. Int. J. Antimicrob. Agents 2016, 47, 269-285. [CrossRef] [PubMed]

72. Galani, I.; Karaiskos, I.; Karantani, I.; Papoutsaki, V.; Maraki, S.; Papaioannou, V.; Kazila, P.; Tsorlini, H.; Charalampaki, N.; Toutouza, M.; et al. Epidemiology and resistance phenotypes of carbapenemase-producing Klebsiella pneumoniae in Greece, 2014 to 2016. Euro Surveill. 2018, 23, 1700775. [CrossRef]

73. Flamm, R.K.; Rhomberg, P.R.; Watters, A.A.; Sweeney, K.; Ellis-Grosse, E.J.; Shortridge, D. Activity of fosfomycin when tested against US contemporary bacterial isolates. Diagn. Microbiol. Infect. Dis. 2019, 93, 143-146. [CrossRef]

74. Dinh, A.; Salomon, J.; Bru, J.P.; Bernard, L. Fosfomycin: Efficacy against infections caused by multidrug-resistant bacteria. Scand. J. Infect. Dis. 2012, 44, 182-189. [CrossRef]

75. Bassetti, M.; Giacobbe, D.R.; Giamarellou, H.; Viscoli, C.; Daikos, G.L.; Dimopoulos, G.; De Rosa, F.G.; Giamarellos-Bourboulis, E.J.; Rossolini, G.M.; Righi, E.; et al. Management of KPC-producing Klebsiella pneumoniae infections. Clin. Microbiol. Infect. 2018, 24, 133-144. [CrossRef]

76. Karageorgopoulos, D.E.; Miriagou, V.; Tzouvelekis, L.S.; Spyridopoulou, K.; Daikos, G.L. Emergence of resistance to fosfomycin used as adjunct therapy in KPC Klebsiella pneumoniae bacteraemia: Report of three cases. J. Antimicrob. Chemother. 2012, 67, 2777-2779. [CrossRef] [PubMed]

77. Yu, W.; Luo, Q.; Shi, Q.; Huang, C.; Yu, X.; Niu, T.; Zhou, K.; Zhang, J.; Xiao, Y. In vitro antibacterial effect of fosfomycin combination therapy against colistin-resistant Klebsiella pneumoniae. Infect. Drug Resist. 2018, 11, 577-585. [CrossRef]

78. Kollef, M.H.; Ricard, J.-D.; Roux, D.; Francois, B.; Ischaki, E.; Rozgonyi, Z.; Boulain, T.; Ivanyi, Z.; János, G.; Garot, D.; et al. A Randomized Trial of the Amikacin Fosfomycin Inhalation System for the Adjunctive Therapy of Gram-Negative VentilatorAssociated Pneumonia: IASIS Trial. Chest 2017, 151, 1239-1246. [CrossRef] [PubMed] 
79. Perdigão Neto, L.V.; Oliveira, M.S.; Martins, R.C.R.; Marchi, A.P.; Gaudereto, J.J.; da Costa, L.A.T.J.; de Lima, L.F.A.; Takeda, C.F.V.; Costa, S.F.; Levin, A.S. Fosfomycin in severe infections due to genetically distinct pan-drug-resistant Gram-negative microorganisms: Synergy with meropenem. J. Antimicrob. Chemother. 2019, 74, 177-181. [CrossRef]

80. Garnacho-Montero, J.; Dimopoulos, G.; Poulakou, G.; Akova, M.; Cisneros, J.M.; De Waele, J.; Petrosillo, N.; Seifert, H.; Timsit, J.F.; Vila, J.; et al. Task force on management and prevention of Acinetobacter baumannii infections in the ICU. Intensive Care Med. 2015, 41, 2057-2075. [CrossRef]

81. Giamarellou, H.; Poulakou, G. Pharmacokinetic and pharmacodynamic evaluation of tigecycline. Expert Opin. Drug Metab. Toxicol. 2011, 7, 1459-1470. [CrossRef] [PubMed]

82. Koomanachai, P.; Kim, A.; Nicolau, D.P. Pharmacodynamic evaluation of tigecycline against Acinetobacter baumannii in a murine pneumonia model. J. Antimicrob. Chemother. 2009, 63, 982-987. [CrossRef]

83. Routsi, C.; Kokkoris, S.; Douka, E.; Ekonomidou, F.; Karaiskos, I.; Giamarellou, H. High-dose tigecycline-associated alterations in coagulation parameters in critically ill patients with severe infections. Int. J. Antimicrob. Agents 2015, 45, 90-93. [CrossRef]

84. Falagas, M.E.; Vardakas, K.Z.; Tsiveriotis, K.P.; Triarides, N.A.; Tansarli, G.S. Effectiveness and safety of high-dose tigecyclinecontaining regimens for the treatment of severe bacterial infections. Int. J. Antimicrob. Agents 2014, 44, 1-7. [CrossRef]

85. Karakonstantis, S. A systematic review of implications, mechanisms, and stability of in vivo emergent resistance to colistin and tigecycline in Acinetobacter baumannii. J. Chemother. 2021, 33, 1-11. [CrossRef]

86. Zavascki, A.P.; Klee, B.O.; Bulitta, J.B. Aminoglycosides against carbapenem-resistant Enterobacteriaceae in the critically ill: The pitfalls of aminoglycoside susceptibility. Exp. Rev. Anti. Infect. Ther. 2017, 15, 519-526. [CrossRef]

87. Ramirez, M.S.; Tolmasky, M.E. Aminoglycoside modifying enzymes. Drug Resist. Update 2010, 13, 151-171. [CrossRef]

88. Tada, T.; Miyoshi-Akiyama, T.; Kato, Y.; Ohmagari, N.; Takeshita, N.; Hung, N.V.; Phuong, D.M.; Thu, T.A.; Binh, N.G.; Anh, N.Q.; et al. Emergence of $16 \mathrm{~S}$ rRNA methylase-producing Acinetobacter baumannii and Pseudomonas aeruginosa isolates in hospitals in Vietnam. BMC Infect. Dis. 2013, 13, 251. [CrossRef]

89. Heidary, M.; Salimi Chirani, A.; Khoshnood, S.; Eslami, G.; Atyabi, S.M.; Nazem, H.; Fazilati, M.; Hashemi, A.; Soleimani, S. Molecular detection of aminoglycoside-modifying enzyme genes in Acinetobacter baumannii clinical isolates. Acta Microbiol. Immunol. Hung. 2017, 64, 143-150. [CrossRef]

90. Sheikhalizadeh, V.; Hasani, A.; Ahangarzadeh Rezaee, M.; Rahmati-Yamchi, M.; Hasani, A.; Ghotaslou, R.; Goli, H.R. Comprehensive study to investigate the role of various aminoglycoside resistance mechanisms in clinical isolates of Acinetobacter baumannii. J. Infect. Chemother. 2017, 23, 74-79. [CrossRef] [PubMed]

91. Garneau-Tsodikova, S.; Labby, K.J. Mechanisms of Resistance to Aminoglycoside Antibiotics: Overview and Perspectives. Medchemcomm 2016, 7, 11-27. [CrossRef] [PubMed]

92. Doi, Y.; Arakawa, Y. $16 \mathrm{~S}$ ribosomal RNA methylation: Emerging resistance mechanism against aminoglycosides. Clin. Infect. Dis. 2007, 45, 88-94. [CrossRef] [PubMed]

93. Berçot, B.; Poirel, L.; Nordmann, P. Updated multiplex polymerase chain reaction for detection of 16S rRNA methylases: High prevalence among NDM-1 producers. Diagn. Microbiol. Infect. Dis. 2011, 71, 442-445. [CrossRef]

94. Zhou, Y.; Yu, H.; Guo, Q.; Xu, X.; Ye, X.; Wu, S.; Guo, Y.; Wang, M. Distribution of 16S rRNA methylases among different species of Gram-negative bacilli with high-level resistance to aminoglycosides. Clin. Microbiol. Infect. Dis. 2010, 29, 1349-1353. [CrossRef] [PubMed]

95. Alexander, B.T.; Marschall, J.; Tibbetts, R.J.; Neuner, E.A.; Dunne, W.M.J.; Ritchie, D.J. Treatment and clinical outcomes of urinary tract infections caused by KPC-producing Enterobacteriaceae in a retrospective cohort. Clin. Ther. 2012, 34, 1314-1323. [CrossRef] [PubMed]

96. Roger, C.; Nucci, B.; Louart, B.; Friggeri, A.; Knani, H.; Evrard, A.; Lavigne, J.-P.; Allaouchiche, B.; Lefrant, J.-Y.; Roberts, J.A.; et al. Impact of $30 \mathrm{mg} / \mathrm{kg}$ amikacin and $8 \mathrm{mg} / \mathrm{kg}$ gentamicin on serum concentrations in critically ill patients with severe sepsis. J. Antimicrob. Chemother. 2016, 71, 208-212. [CrossRef] [PubMed]

97. Van Duin, D.; Cober, E.; Richter, S.S.; Perez, F.; Kalayjian, R.C.; Salata, R.A.; Evans, S.; Fowler, V.G.J.; Kaye, K.S.; Bonomo, R.A. Impact of therapy and strain type on outcomes in urinary tract infections caused by carbapenem-resistant Klebsiella pneumoniae. J. Antimicrob. Chemother. 2015, 70, 1203-1211. [CrossRef] [PubMed]

98. Paquette, F.; Bernier-Jean, A.; Brunette, V.; Ammann, H.; Lavergne, V.; Pichette, V.; Troyanov, S.; Bouchard, J. Acute Kidney Injury and Renal Recovery with the Use of Aminoglycosides: A Large Retrospective Study. Nephron 2015, 131, 153-160. [CrossRef] [PubMed]

99. Jean, S.-S.; Gould, I.M.; Lee, W.-S.; Hsueh, P.-R. New Drugs for Multidrug-Resistant Gram-Negative Organisms: Time for Stewardship. Drugs 2019, 79, 705-714. [CrossRef]

100. Wilson, G.M.; Fitzpatrick, M.; Walding, K.; Gonzalez, B.; Schweizer, M.L.; Suda, K.J.; Evans, C.T. Meta-analysis of Clinical Outcomes Using Ceftazidime/Avibactam, Ceftolozane/Tazobactam, and Meropenem/Vaborbactam for the Treatment of Multidrug-Resistant Gram-Negative Infections. Open Forum Infect. Dis. 2021, 8, ofaa651. [CrossRef]

101. Karaiskos, I.; Galani, I.; Souli, M.; Giamarellou, H. Novel $\beta$-lactam- $\beta$-lactamase inhibitor combinations: Expectations for the treatment of carbapenem-resistant Gram-negative pathogens. Expert Opin. Drug Metab. Toxicol. 2019, 15, 133-149. [CrossRef]

102. De Jonge, B.L.M.; Karlowsky, J.A.; Kazmierczak, K.M.; Biedenbach, D.J.; Sahm, D.F.; Nichols, W.W. In Vitro Susceptibility to Ceftazidime-Avibactam of Carbapenem-Nonsusceptible Enterobacteriaceae Isolates Collected during the INFORM Global Surveillance Study (2012 to 2014). Antimicrob. Agents Chemother. 2016, 60, 3163-3169. [CrossRef] 
103. Lahiri, S.D.; Johnstone, M.R.; Ross, P.L.; McLaughlin, R.E.; Olivier, N.B.; Alm, R.A. Avibactam and class C $\beta$-lactamases: Mechanism of inhibition, conservation of the binding pocket, and implications for resistance. Antimicrob. Agents Chemother. 2014, 58, 5704-5713. [CrossRef]

104. Karlowsky, J.A.; Biedenbach, D.J.; Kazmierczak, K.M.; Stone, G.G.; Sahm, D.F. Activity of Ceftazidime-Avibactam against Extended-Spectrum- and AmpC $\beta$-Lactamase-Producing Enterobacteriaceae Collected in the INFORM Global Surveillance Study from 2012 to 2014. Antimicrob. Agents Chemother. 2016, 60, 2849-2857. [CrossRef] [PubMed]

105. Shields, R.K.; Nguyen, M.H.; Chen, L.; Press, E.G.; Potoski, B.A.; Marini, R.V.; Doi, Y.; Kreiswirth, B.N.; Clancy, C.J. CeftazidimeAvibactam Is Superior to Other Treatment Regimens against Carbapenem-Resistant Klebsiella pneumoniae Bacteremia. Antimicrob. Agents Chemother. 2017, 61, e00883-17. [CrossRef] [PubMed]

106. Van Duin, D.; Lok, J.J.; Earley, M.; Cober, E.; Richter, S.S.; Perez, F.; Salata, R.A.; Kalayjian, R.C.; Watkins, R.R.; Doi, Y.; et al. Colistin Versus Ceftazidime-Avibactam in the Treatment of Infections Due to Carbapenem-Resistant Enterobacteriaceae. Clin. Infect. Dis. 2018, 66, 163-171. [CrossRef]

107. Van Asten, S.A.V.; Boattini, M.; Kraakman, M.E.M.; Bianco, G.; Iannaccone, M.; Costa, C.; Cavallo, R.; Bernards, A.T. Ceftazidimeavibactam resistance and restoration of carbapenem susceptibility in KPC-producing Klebsiella pneumoniae infections: A case series. J. Infect. Chemother. 2021, 27, 778-780. [CrossRef]

108. Shapiro, A.B.; Moussa, S.H.; Carter, N.M.; Gao, N.; Miller, A.A. Ceftazidime-Avibactam Resistance Mutations V240G, D179Y, and D179Y/T243M in KPC-3 ß-Lactamase Do Not Alter Cefpodoxime-ETX1317 Susceptibility. ACS Infect. Dis. 2021, 7, 79-87. [CrossRef]

109. Pagès, J.-M.; Peslier, S.; Keating, T.A.; Lavigne, J.-P.; Nichols, W.W. Role of the Outer Membrane and Porins in Susceptibility of $\beta$-Lactamase-Producing Enterobacteriaceae to Ceftazidime-Avibactam. Antimicrob. Agents Chemother. 2015, 60, 1349-1359. [CrossRef]

110. Huang, Y.; Wu, T.; Perez, O.; Rana, A.P.; Chen, L.; Kreiswirth, B.N.; Satlin, M.J.; Bulman, Z.P. In vitro Optimization of Ceftazidime/Avibactam for KPC-Producing Klebsiella pneumoniae. Front. Microbiol. 2021, 12, 414. [CrossRef]

111. Yin, D.; Wu, S.; Yang, Y.; Shi, Q.; Dong, D.; Zhu, D.; Hu, F. Results from the China Antimicrobial Surveillance Network (CHINET) in 2017 of the In Vitro Activities of Ceftazidime-Avibactam and Ceftolozane-Tazobactam against Clinical Isolates of Enterobacteriaceae and Pseudomonas aeruginosa. Antimicrob. Agents Chemother. 2019, 63, e02431-18. [CrossRef]

112. Cluck, D.; Lewis, P.; Stayer, B.; Spivey, J.; Moorman, J. Ceftolozane-tazobactam: A new-generation cephalosporin. Am. J. Health Pharm. AJHP Off. J. Am. Soc. Health Pharm. 2015, 72, 2135-2146. [CrossRef] [PubMed]

113. Pfaller, M.A.; Bassetti, M.; Duncan, L.R.; Castanheira, M. Ceftolozane/tazobactam activity against drug-resistant Enterobacteriaceae and Pseudomonas aeruginosa causing urinary tract and intraabdominal infections in Europe: Report from an antimicrobial surveillance programme (2012-2015). J. Antimicrob. Chemother. 2017, 72, 1386-1395. [CrossRef]

114. Saran, O.; Sulik-Tyszka, B.; Basak, G.W.; Wróblewska, M.M. Activity of Ceftolozane/Tazobactam Against Gram-Negative Rods of the Family Enterobacteriaceae and Pseudomonas Spp. Isolated from Onco-Hematological Patients Hospitalized in a Clinical Hospital in Poland. Med. Sci. Monit. Int. Med. J. Exp. Clin. Res. 2019, 25, 305-311. [CrossRef] [PubMed]

115. Castanheira, M.; Duncan, L.R.; Mendes, R.E.; Sader, H.S.; Shortridge, D. Activity of Ceftolozane-Tazobactam against Pseudomonas aeruginosa and Enterobacteriaceae Isolates Collected from Respiratory Tract Specimens of Hospitalized Patients in the United States during 2013 to 2015. Antimicrob. Agents Chemother. 2018, 62, e02125-17. [CrossRef]

116. Castanheira, M.; Doyle, T.B.; Mendes, R.E.; Sader, H.S. Comparative Activities of Ceftazidime-Avibactam and CeftolozaneTazobactam against Enterobacteriaceae Isolates Producing Extended-Spectrum $\beta$-Lactamases from U.S. Hospitals. Antimicrob. Agents Chemother. 2019, 63, e00160-19. [CrossRef] [PubMed]

117. Popejoy, M.W.; Paterson, D.L.; Cloutier, D.; Huntington, J.A.; Miller, B.; Bliss, C.A.; Steenbergen, J.N.; Hershberger, E.; Umeh, O.; Kaye, K.S. Efficacy of ceftolozane/tazobactam against urinary tract and intra-abdominal infections caused by ESBL-producing Escherichia coli and Klebsiella pneumoniae: A pooled analysis of Phase 3 clinical trials. J. Antimicrob. Chemother. 2017, 72, 268-272. [CrossRef]

118. Lee, Y.; Kim, J.; Trinh, S. Meropenem-Vaborbactam (Vabomere $\left.\left({ }^{\mathrm{TM}}\right)\right)$ : Another Option for Carbapenem-Resistant Enterobacteriaceae. P T 2019, 44, 110-113. [PubMed]

119. Maraki, S.; Mavromanolaki, V.E.; Moraitis, P.; Stafylaki, D.; Kasimati, A.; Magkafouraki, E.; Scoulica, E. Ceftazidime-avibactam, meropenen-vaborbactam, and imipenem-relebactam in combination with aztreonam against multidrug-resistant, metallo- $\beta$ lactamase-producing Klebsiella pneumoniae. Eur. J. Clin. Microbiol. Infect. Dis. 2021. [CrossRef]

120. Haidar, G.; Clancy, C.J.; Chen, L.; Samanta, P.; Shields, R.K.; Kreiswirth, B.N.; Nguyen, M.H. Identifying Spectra of Activity and Therapeutic Niches for Ceftazidime-Avibactam and Imipenem-Relebactam against Carbapenem-Resistant Enterobacteriaceae. Antimicrob. Agents Chemother. 2017, 61, e00642-17. [CrossRef]

121. Karlowsky, J.A.; Lob, S.H.; Kazmierczak, K.M.; Hawser, S.P.; Magnet, S.; Young, K.; Motyl, M.R.; Sahm, D.F. In vitro activity of imipenem/relebactam against Gram-negative ESKAPE pathogens isolated in 17 European countries: 2015 SMART surveillance programme. J. Antimicrob. Chemother. 2018, 73, 1872-1879. [CrossRef]

122. Mushtaq, S.; Meunier, D.; Vickers, A.; Woodford, N.; Livermore, D.M. Activity of imipenem/relebactam against Pseudomonas aeruginosa producing ESBLs and carbapenemases. J. Antimicrob. Chemother. 2021, 76, 434-442. [CrossRef]

123. Livermore, D.M.; Warner, M.; Mushtaq, S. Activity of MK-7655 combined with imipenem against Enterobacteriaceae and Pseudomonas aeruginosa. J. Antimicrob. Chemother. 2013, 68, 2286-2290. [CrossRef] 
124. Canver, M.C.; Satlin, M.J.; Westblade, L.F.; Kreiswirth, B.N.; Chen, L.; Robertson, A.; Fauntleroy, K.; La Spina, M.; Callan, K.; Jenkins, S.G. Activity of Imipenem-Relebactam and Comparator Agents against Genetically Characterized Isolates of CarbapenemResistant Enterobacteriaceae. Antimicrob. Agents Chemother. 2019, 63, e00672-19. [CrossRef] [PubMed]

125. Yang, Q.; Zhang, H.; Yu, Y.; Kong, H.; Duan, Q.; Wang, Y.; Zhang, S.; Sun, Z.; Liao, K.; Gu, L.; et al. In Vitro Activity of Imipenem/Relebactam Against Enterobacteriaceae Isolates Obtained from Intra-abdominal, Respiratory Tract, and Urinary Tract Infections in China: Study for Monitoring Antimicrobial Resistance Trends (SMART), 2015-2018. Clin. Infect. Dis. Off. Publ. Infect. Dis. Soc. Am. 2020, 71, S427-S435. [CrossRef] [PubMed]

126. Lob, S.H.; Karlowsky, J.A.; Young, K.; Motyl, M.R.; Hawser, S.; Kothari, N.D.; Sahm, D.F. In vitro activity of imipenem-relebactam against resistant phenotypes of Enterobacteriaceae and Pseudomonas aeruginosa isolated from intraabdominal and urinary tract infection samples-SMART Surveillance Europe 2015-2017. J. Med. Microbiol. 2020, 69, 207-217. [CrossRef] [PubMed]

127. Ackley, R.; Roshdy, D.; Meredith, J.; Minor, S.; Anderson, W.E.; Capraro, G.A.; Polk, C. Meropenem-Vaborbactam versus Ceftazidime-Avibactam for Treatment of Carbapenem-Resistant Enterobacteriaceae Infections. Antimicrob. Agents Chemother. 2020, 64, e02313-19. [CrossRef]

128. Kaye, K.S.; Vazquez, J.; Mathers, A.; Daikos, G.; Alexander, E.; Loutit, J.S.; Zhang, S.; Dudley, M.N.; Cornely, O. Clinical Outcomes of Serious Infections due to Carbapenem-Resistant Enterobacteriaceae (CRE) in TANGO II, a Phase 3, Randomized, MultiNational, Open-Label Trial of Meropenem-Vaborbactam (M-V) Vs. Best Available Therapy (BAT). Open Forum Infect. Dis. 2017, 4, S534-S535. [CrossRef]

129. Kaye, K.S.; Bhowmick, T.; Metallidis, S.; Bleasdale, S.C.; Sagan, O.S.; Stus, V.; Vazquez, J.; Zaitsev, V.; Bidair, M.; Chorvat, E.; et al. Effect of Meropenem-Vaborbactam vs Piperacillin-Tazobactam on Clinical Cure or Improvement and Microbial Eradication in Complicated Urinary Tract Infection: The TANGO I Randomized Clinical Trial. JAMA 2018, 319, 788-799. [CrossRef]

130. Carvalhaes, C.G.; Shortridge, D.; Sader, H.S.; Castanheira, M. Activity of Meropenem-Vaborbactam against Bacterial Isolates Causing Pneumonia in Patients in U.S. Hospitals during 2014 to 2018. Antimicrob. Agents Chemother. 2020, 64, e02177-19. [CrossRef]

131. Moya, B.; Barcelo, I.M.; Bhagwat, S.; Patel, M.; Bou, G.; Papp-Wallace, K.M.; Bonomo, R.A.; Oliver, A. WCK 5107 (Zidebactam) and WCK 5153 Are Novel Inhibitors of PBP2 Showing Potent " $\beta$-Lactam Enhancer" Activity against Pseudomonas aeruginosa, Including Multidrug-Resistant Metallo- $\beta$-Lactamase-Producing High-Risk Clones. Antimicrob. Agents Chemother. 2017, 61, e02529-16. [CrossRef]

132. Moya, B.; Barcelo, I.M.; Bhagwat, S.; Patel, M.; Bou, G.; Papp-Wallace, K.M.; Bonomo, R.A.; Oliver, A. Potent $\beta$-Lactam Enhancer Activity of Zidebactam and WCK 5153 against Acinetobacter baumannii, Including Carbapenemase-Producing Clinical Isolates. Antimicrob. Agents Chemother. 2017, 61, e01238-17. [CrossRef]

133. Karlowsky, J.A.; Hackel, M.A.; Bouchillon, S.K.; Sahm, D.F. In Vitro Activity of WCK 5222 (Cefepime-Zidebactam) against Worldwide Collected Gram-Negative Bacilli Not Susceptible to Carbapenems. Antimicrob. Agents Chemother. 2020, 64, e01432-20. [CrossRef]

134. Yang, Y.; Guo, Y.; Yin, D.; Zheng, Y.; Wu, S.; Zhu, D.; Hu, F. In Vitro Activity of Cefepime-Zidebactam, Ceftazidime-Avibactam, and Other Comparators against Clinical Isolates of Enterobacterales, Pseudomonas aeruginosa, and Acinetobacter baumannii: Results from China Antimicrobial Surveillance Network (CHINET) in 2018. Antimicrob. Agents Chemother. 2020, 65, e01726-20. [CrossRef] [PubMed]

135. Rodvold, K.A.; Gotfried, M.H.; Chugh, R.; Gupta, M.; Patel, A.; Chavan, R.; Yeole, R.; Friedland, H.D.; Bhatia, A. Plasma and Intrapulmonary Concentrations of Cefepime and Zidebactam following Intravenous Administration of WCK 5222 to Healthy Adult Subjects. Antimicrob. Agents Chemother. 2018, 62. [CrossRef] [PubMed]

136. Papp-Wallace, K.M. The latest advances in $\beta$-lactam/ $\beta$-lactamase inhibitor combinations for the treatment of Gram-negative bacterial infections. Expert Opin. Pharmacother. 2019, 20, 2169-2184. [CrossRef]

137. Zhang, H.; Xu, Y.; Jia, P.; Zhu, Y.; Zhang, G.; Zhang, J.; Duan, S.; Kang, W.; Wang, T.; Jing, R.; et al. Global trends of antimicrobial susceptibility to ceftaroline and ceftazidime-avibactam: A surveillance study from the ATLAS program (2012-2016). Antimicrob. Resist. Infect. Control 2020, 9, 166. [CrossRef]

138. Justo, J.A.; Mayer, S.M.; Pai, M.P.; Soriano, M.M.; Danziger, L.H.; Novak, R.M.; Rodvold, K.A. Pharmacokinetics of ceftaroline in normal body weight and obese (classes I, II, and III) healthy adult subjects. Antimicrob. Agents Chemother. 2015, 59, 3956-3965. [CrossRef]

139. Vrancianu, C.O.; Gheorghe, I.; Dobre, E.-G.; Barbu, I.C.; Cristian, R.E.; Popa, M.; Lee, S.H.; Limban, C.; Vlad, I.M.; Chifiriuc, M.C. Emerging Strategies to Combat $\beta$-Lactamase Producing ESKAPE Pathogens. Int. J. Mol. Sci. 2020, 21, 8527. [CrossRef]

140. Castanheira, M.; Sader, H.S.; Farrell, D.J.; Mendes, R.E.; Jones, R.N. Activity of ceftaroline-avibactam tested against Gramnegative organism populations, including strains expressing one or more $\beta$-lactamases and methicillin-resistant Staphylococcus aureus carrying various staphylococcal cassette chromosome mec types. Antimicrob. Agents Chemother. 2012, 56, $4779-4785$. [CrossRef] [PubMed]

141. Castanheira, M.; Williams, G.; Jones, R.N.; Sader, H.S. Activity of ceftaroline-avibactam tested against contemporary Enterobacteriaceae isolates carrying $\beta$-lactamases prevalent in the United States. Microb. Drug Resist. 2014, 20, 436-440. [CrossRef] [PubMed]

142. Khalid, A.; Lubián, A.F.; Ma, L.; Lin, R.C.Y.; Iredell, J.R. Characterizing the role of porin mutations in susceptibility of beta lactamase producing Klebsiella pneumoniae isolates to ceftaroline and ceftaroline-avibactam. Int. J. Infect. Dis. 2020, 93, 252-257. [CrossRef]

143. Wu, J.Y.; Srinivas, P.; Pogue, J.M. Cefiderocol: A Novel Agent for the Management of Multidrug-Resistant Gram-Negative Organisms. Infect. Dis. Ther. 2020, 9, 17-40. [CrossRef] [PubMed] 
144. Lee, Y.R.; Yeo, S. Cefiderocol, a New Siderophore Cephalosporin for the Treatment of Complicated Urinary Tract Infections Caused by Multidrug-Resistant Pathogens: Preclinical and Clinical Pharmacokinetics, Pharmacodynamics, Efficacy and Safety. Clin. Drug Investig. 2020, 40, 901-913. [CrossRef]

145. Ito, A.; Sato, T.; Ota, M.; Takemura, M.; Nishikawa, T.; Toba, S.; Kohira, N.; Miyagawa, S.; Ishibashi, N.; Matsumoto, S.; et al. In Vitro Antibacterial Properties of Cefiderocol, a Novel Siderophore Cephalosporin, against Gram-Negative Bacteria. Antimicrob. Agents Chemother. 2018, 62, e01454-17. [CrossRef]

146. Jacobs, M.R.; Abdelhamed, A.M.; Good, C.E.; Rhoads, D.D.; Hujer, K.M.; Hujer, A.M.; Domitrovic, T.N.; Rudin, S.D.; Richter, S.S.; van Duin, D.; et al. ARGONAUT-I: Activity of Cefiderocol (S-649266), a Siderophore Cephalosporin, against Gram-Negative Bacteria, Including Carbapenem-Resistant Nonfermenters and Enterobacteriaceae with Defined Extended-Spectrum $\beta$-Lactamases and Carbapenemases. Antimicrob. Agents Chemother. 2019, 63, e01801-18. [CrossRef] [PubMed]

147. Karlowsky, J.A.; Hackel, M.A.; Tsuji, M.; Yamano, Y.; Echols, R.; Sahm, D.F. In Vitro Activity of Cefiderocol, a Siderophore Cephalosporin, Against Gram-Negative Bacilli Isolated by Clinical Laboratories in North America and Europe in 2015-2016: SIDERO-WT-2015. Int. J. Antimicrob. Agents 2019, 53, 456-466. [CrossRef] [PubMed]

148. Monogue, M.L.; Tsuji, M.; Yamano, Y.; Echols, R.; Nicolau, D.P. Efficacy of Humanized Exposures of Cefiderocol (S-649266) against a Diverse Population of Gram-Negative Bacteria in a Murine Thigh Infection Model. Antimicrob. Agents Chemother. 2017, 61, e01022-17. [CrossRef] [PubMed]

149. Matsumoto, S.; Singley, C.M.; Hoover, J.; Nakamura, R.; Echols, R.; Rittenhouse, S.; Tsuji, M.; Yamano, Y. Efficacy of Cefiderocol against Carbapenem-Resistant Gram-Negative Bacilli in Immunocompetent-Rat Respiratory Tract Infection Models Recreating Human Plasma Pharmacokinetics. Antimicrob. Agents Chemother. 2017, 61, e00700-17. [CrossRef]

150. Bassetti, M.; Echols, R.; Matsunaga, Y.; Ariyasu, M.; Doi, Y.; Ferrer, R.; Lodise, T.P.; Naas, T.; Niki, Y.; Paterson, D.L.; et al. Efficacy and safety of cefiderocol or best available therapy for the treatment of serious infections caused by carbapenem-resistant Gram-negative bacteria (CREDIBLE-CR): A randomised, open-label, multicentre, pathogen-focused, descriptive, phase 3 trial. Lancet Infect. Dis. 2021, 21, 226-240. [CrossRef]

151. Wunderink, R.G.; Matsunaga, Y.; Ariyasu, M.; Clevenbergh, P.; Echols, R.; Kaye, K.S.; Kollef, M.; Menon, A.; Pogue, J.M.; Shorr, A.F.; et al. Cefiderocol versus high-dose, extended-infusion meropenem for the treatment of Gram-negative nosocomial pneumonia (APEKS-NP): A randomised, double-blind, phase 3, non-inferiority trial. Lancet Infect. Dis. 2021, 21, 213-225. [CrossRef]

152. Chew, K.L.; Tay, M.K.L.; Cheng, B.; Lin, R.T.P.; Octavia, S.; Teo, J.W.P. Aztreonam-Avibactam Combination Restores Susceptibility of Aztreonam in Dual-Carbapenemase-Producing Enterobacteriaceae. Antimicrob. Agents Chemother. 2018, 62, e00414-18. [CrossRef]

153. Ransom, E.; Bhatnagar, A.; Patel, J.B.; Machado, M.-J.; Boyd, S.; Reese, N.; Lutgring, J.D.; Lonsway, D.; Anderson, K.; Brown, A.C.; et al. Validation of Aztreonam-Avibactam Susceptibility Testing Using Digitally Dispensed Custom Panels. J. Clin. Microbiol. 2020, 58, e01944-19. [CrossRef]

154. Bhatnagar, A.; Ransom, E.M.; Machado, M.-J.; Boyd, S.; Reese, N.; Anderson, K.; Lonsway, D.; Elkins, C.A.; Rasheed, J.K.; Patel, J.B.; et al. Assessing the in vitro impact of ceftazidime on aztreonam/avibactam susceptibility testing for highly resistant MBL-producing Enterobacterales. J. Antimicrob. Chemother. 2021, 76, 979-983. [CrossRef] [PubMed]

155. Kim, T.; Lee, S.C.; Bae, M.; Sung, H.; Kim, M.-N.; Jung, J.; Kim, M.J.; Kim, S.-H.; Lee, S.-O.; Choi, S.-H.; et al. In Vitro Activities and Inoculum Effects of Ceftazidime-Avibactam and Aztreonam-Avibactam against Carbapenem-Resistant Enterobacterales Isolates from South Korea. Antibiotics 2020, 9, 912. [CrossRef]

156. Monogue, M.L.; Giovagnoli, S.; Bissantz, C.; Zampaloni, C.; Nicolau, D.P. In Vivo Efficacy of Meropenem with a Novel Non- $\beta$ Lactam- $\beta$-Lactamase Inhibitor, Nacubactam, against Gram-Negative Organisms Exhibiting Various Resistance Mechanisms in a Murine Complicated Urinary Tract Infection Model. Antimicrob. Agents Chemother. 2018, 62, e02596-17. [CrossRef] [PubMed]

157. Morinaka, A.; Tsutsumi, Y.; Yamada, M.; Suzuki, K.; Watanabe, T.; Abe, T.; Furuuchi, T.; Inamura, S.; Sakamaki, Y.; Mitsuhashi, N.; et al. OP0595, a new diazabicyclooctane: Mode of action as a serine $\beta$-lactamase inhibitor, antibiotic and $\beta$-lactam "enhancer". J. Antimicrob. Chemother. 2015, 70, 2779-2786. [CrossRef]

158. Barnes, M.D.; Taracila, M.A.; Good, C.E.; Bajaksouzian, S.; Rojas, L.J.; van Duin, D.; Kreiswirth, B.N.; Jacobs, M.R.; Haldimann, A.; Papp-Wallace, K.M.; et al. Nacubactam Enhances Meropenem Activity against Carbapenem-Resistant Klebsiella pneumoniae Producing KPC. Antimicrob. Agents Chemother. 2019, 63, e00432-19. [CrossRef]

159. Papp-Wallace, K.M.; Bonomo, R.A. New $\beta$-Lactamase Inhibitors in the Clinic. Infect. Dis. Clin. North Am. 2016, 30, 441-464. [CrossRef] [PubMed]

160. Mushtaq, S.; Vickers, A.; Woodford, N.; Haldimann, A.; Livermore, D.M. Activity of nacubactam (RG6080/OP0595) combinations against MBL-producing Enterobacteriaceae. J. Antimicrob. Chemother. 2019, 74, 953-960. [CrossRef] [PubMed]

161. Landman, D.; Kelly, P.; Bäcker, M.; Babu, E.; Shah, N.; Bratu, S.; Quale, J. Antimicrobial activity of a novel aminoglycoside, ACHN-490, against Acinetobacter baumannii and Pseudomonas aeruginosa from New York City. J. Antimicrob. Chemother. 2011, 66, 332-334. [CrossRef]

162. Karpiuk, I.; Tyski, S. Looking for new preparations for antibacterial therapy. IV. New antimicrobial agents from the aminoglycoside, macrolide and tetracycline groups in clinical trials. Przegl. Epidemiol. 2015, 69, 723-729.

163. Syue, L.-S.; Chen, Y.-H.; Ko, W.-C.; Hsueh, P.-R. New drugs for the treatment of complicated intra-abdominal infections in the era of increasing antimicrobial resistance. Int. J. Antimicrob. Agents 2016, 47, 250-258. [CrossRef] [PubMed]

164. Mingeot-Leclercq, M.P.; Glupczynski, Y.; Tulkens, P.M. Aminoglycosides: Activity and resistance. Antimicrob. Agents Chemother. 1999, 43, 727-737. [CrossRef] [PubMed] 
165. Jacobs, M.R.; Good, C.E.; Hujer, A.M.; Abdelhamed, A.M.; Rhoads, D.D.; Hujer, K.M.; Rudin, S.D.; Domitrovic, T.N.; Connolly, L.E.; Krause, K.M.; et al. ARGONAUT II Study of the In Vitro Activity of Plazomicin against CarbapenemaseProducing Klebsiella pneumoniae. Antimicrob. Agents Chemother. 2020, 64, e00012-20. [CrossRef]

166. Fleischmann, W.A.; Greenwood-Quaintance, K.E.; Patel, R. In Vitro Activity of Plazomicin Compared to Amikacin, Gentamicin, and Tobramycin against Multidrug-Resistant Aerobic Gram-Negative Bacilli. Antimicrob. Agents Chemother. 2020, 64, e01711-19. [CrossRef] [PubMed]

167. Clark, J.A.; Kulengowski, B.; Burgess, D.S. In vitro activity of plazomicin compared to other clinically relevant aminoglycosides in carbapenem-resistant Enterobacteriaceae. Diagn. Microbiol. Infect. Dis. 2020, 98, 115117. [CrossRef] [PubMed]

168. Castanheira, M.; Sader, H.S.; Mendes, R.E.; Jones, R.N. Activity of Plazomicin Tested against Enterobacterales Isolates Collected from U.S. Hospitals in 2016-2017: Effect of Different Breakpoint Criteria on Susceptibility Rates among Aminoglycosides. Antimicrob. Agents Chemother. 2020, 64, e02418-19. [CrossRef]

169. Walkty, A.; Adam, H.; Baxter, M.; Denisuik, A.; Lagacé-Wiens, P.; Karlowsky, J.A.; Hoban, D.J.; Zhanel, G.G. In vitro activity of plazomicin against 5,015 gram-negative and gram-positive clinical isolates obtained from patients in canadian hospitals as part of the CANWARD study, 2011-2012. Antimicrob. Agents Chemother. 2014, 58, 2554-2563. [CrossRef]

170. Denervaud-Tendon, V.; Poirel, L.; Connolly, L.E.; Krause, K.M.; Nordmann, P. Plazomicin activity against polymyxin-resistant Enterobacteriaceae, including MCR-1-producing isolates. J. Antimicrob. Chemother. 2017, 72, 2787-2791. [CrossRef]

171. Shaeer, K.M.; Zmarlicka, M.T.; Chahine, E.B.; Piccicacco, N.; Cho, J.C. Plazomicin: A Next-Generation Aminoglycoside. Pharmacotherapy 2019, 39, 77-93. [CrossRef]

172. Doi, Y.; Wachino, J.-I.; Arakawa, Y. Aminoglycoside Resistance: The Emergence of Acquired 16S Ribosomal RNA Methyltransferases. Infect. Dis. Clin. North Am. 2016, 30, 523-537. [CrossRef]

173. Castanheira, M.; Streit, J.M.; Serio, A.W.; Krause, K.M.; Flamm, R.K. 1345. Comparative Activity of Plazomicin and Other Aminoglycosides Against Enterobacteriaceae Isolates from Various Infection Sources from Hospitalized Patients in the United States. Open Forum Infect. Dis. 2018, 5, S411. [CrossRef]

174. Cox, G.; Ejim, L.; Stogios, P.J.; Koteva, K.; Bordeleau, E.; Evdokimova, E.; Sieron, A.O.; Savchenko, A.; Serio, A.W.; Krause, K.M.; et al. Plazomicin Retains Antibiotic Activity against Most Aminoglycoside Modifying Enzymes. ACS Infect. Dis. 2018, 4, 980-987. [CrossRef]

175. Reyes, N.; Aggen, J.B.; Kostrub, C.F. In vivo efficacy of the novel aminoglycoside ACHN-490 in murine infection models. Antimicrob. Agents Chemother. 2011, 55, 1728-1733. [CrossRef]

176. Drusano, G.L.; Liu, W.; Fikes, S.; Cirz, R.; Robbins, N.; Kurhanewicz, S.; Rodriquez, J.; Brown, D.; Baluya, D.; Louie, A. Interaction of drug- and granulocyte-mediated killing of Pseudomonas aeruginosa in a murine pneumonia model. J. Infect. Dis. 2014, 210, 1319-1324. [CrossRef]

177. Layton, R.C.; Brasel, T.; Gigliotti, A.; Barr, E.; Storch, S.; Myers, L.; Hobbs, C.; Koster, F. Primary pneumonic plague in the African Green monkey as a model for treatment efficacy evaluation. J. Med. Primatol. 2011, 40, 6-17. [CrossRef]

178. Mega, W.; Overheim, K.; Cirz, R.; Cass, R.; Valderas, M.; Sherwood, R. Telemetry used to determine efficacy of intravenous plazomicin against inhaled tularemia in cynomolgus macaques (CM). J. Pharmacol. Toxicol. Methods 2014, 70, 334. [CrossRef]

179. Gall, J.; Choi, T.; Riddle, V.; Van Wart, S.; Gibbons, J.A.; Seroogy, J. A Phase 1 Study of Intravenous Plazomicin in Healthy Adults to Assess Potential Effects on the QT/QTc Interval, Safety, and Pharmacokinetics. Clin. Pharmacol. Drug. Dev. 2019, 8, 1032-1041. [CrossRef]

180. Connolly, L.E.; Riddle, V.; Cebrik, D.; Armstrong, E.S.; Miller, L.G. A Multicenter, Randomized, Double-Blind, Phase 2 Study of the Efficacy and Safety of Plazomicin Compared with Levofloxacin in the Treatment of Complicated Urinary Tract Infection and Acute Pyelonephritis. Antimicrob. Agents Chemother. 2018, 62, e01989-17. [CrossRef] [PubMed]

181. Kuti, J.L.; Kim, A.; Cloutier, D.J.; Nicolau, D.P. Evaluation of Plazomicin, Tigecycline, and Meropenem Pharmacodynamic Exposure against Carbapenem-Resistant Enterobacteriaceae in Patients with Bloodstream Infection or Hospital-Acquired/VentilatorAssociated Pneumonia from the CARE Study (ACHN-490-007). Infect. Dis. Ther. 2019, 8, 383-396. [CrossRef] [PubMed]

182. Wagenlehner, F.M.E.; Cloutier, D.J.; Komirenko, A.S.; Cebrik, D.S.; Krause, K.M.; Keepers, T.R.; Connolly, L.E.; Miller, L.G.; Friedland, I.; Dwyer, J.P. Once-Daily Plazomicin for Complicated Urinary Tract Infections. N. Engl. J. Med. 2019, 380, 729-740. [CrossRef]

183. Solomkin, J.; Evans, D.; Slepavicius, A.; Lee, P.; Marsh, A.; Tsai, L.; Sutcliffe, J.A.; Horn, P. Assessing the Efficacy and Safety of Eravacycline vs Ertapenem in Complicated Intra-abdominal Infections in the Investigating Gram-Negative Infections Treated With Eravacycline (IGNITE 1) Trial: A Randomized Clinical Trial. JAMA Surg. 2017, 152, 224-232. [CrossRef]

184. Lee, Y.R.; Burton, C.E. Eravacycline, a newly approved fluorocycline. Eur. J. Clin. Microbiol. Infect. Dis. 2019, 38, 1787-1794. [CrossRef]

185. Connors, K.P.; Housman, S.T.; Pope, J.S.; Russomanno, J.; Salerno, E.; Shore, E.; Redican, S.; Nicolau, D.P. Phase I, Open-Label, Safety and Pharmacokinetic Study to Assess Bronchopulmonary Disposition of Intravenous Eravacycline in Healthy Men and Women. Antimicrob. Agents Chemother. 2014, 58, 2113-2118. [CrossRef]

186. Solomkin, J.S.; Ramesh, M.K.; Cesnauskas, G.; Novikovs, N.; Stefanova, P.; Sutcliffe, J.A.; Walpole, S.M.; Horn, P.T. Phase 2, randomized, double-blind study of the efficacy and safety of two dose regimens of eravacycline versus ertapenem for adult community-acquired complicated intra-abdominal infections. Antimicrob. Agents Chemother. 2014, 58, 1847-1854. [CrossRef]

187. Solomkin, J.S.; Gardovskis, J.; Lawrence, K.; Montravers, P.; Sway, A.; Evans, D.; Tsai, L. IGNITE4: Results of a Phase 3, Randomized, Multicenter, Prospective Trial of Eravacycline vs Meropenem in the Treatment of Complicated Intraabdominal Infections. Clin. Infect. Dis. 2019, 69, 921-929. [CrossRef]

188. Gallagher, J.C. Omadacycline: A Modernized Tetracycline. Clin. Infect. Dis. 2019, 69, S1-S5. [CrossRef] 
189. Watkins, R.R.; Deresinski, S. Omadacycline: A Novel Tetracycline Derivative with Oral and Intravenous Formulations. Clin. Infect. Dis. 2019, 69, 890-896. [CrossRef]

190. Karlowsky, J.A.; Steenbergen, J.; Zhanel, G.G. Microbiology and Preclinical Review of Omadacycline. Clin. Infect. Dis. 2019, 69, S6-S15. [CrossRef] [PubMed]

191. Zhanel, G.G.; Esquivel, J.; Zelenitsky, S.; Lawrence, C.K.; Adam, H.J.; Golden, A.; Hink, R.; Berry, L.; Schweizer, F.; Zhanel, M.A.; et al. Omadacycline: A Novel Oral and Intravenous Aminomethylcycline Antibiotic Agent. Drugs 2020, 80, 285-313. [CrossRef]

192. Huband, M.D.; Pfaller, M.A.; Shortridge, D.; Flamm, R.K. Surveillance of omadacycline activity tested against clinical isolates from the United States and Europe: Results from the SENTRY Antimicrobial Surveillance Programme, 2017. J. Glob. Antimicrob. Resist. 2019, 19, 56-63. [CrossRef]

193. Lin, W.; Flarakos, J.; Du, Y.; Hu, W.; He, H.; Mangold, J.; Tanaka, S.K.; Villano, S. Pharmacokinetics, Distribution, Metabolism, and Excretion of Omadacycline following a Single Intravenous or Oral Dose of 14C-Omadacycline in Rats. Antimicrob. Agents Chemother. 2017, 61, e01784-16. [CrossRef]

194. Lepak, A.J.; Zhao, M.; Marchillo, K.; VanHecker, J.; Andes, D.R. In Vivo Pharmacodynamic Evaluation of Omadacycline (PTK 0796) against Streptococcus pneumoniae in the Murine Pneumonia Model. Antimicrob. Agents Chemother. 2017, 61, e02368-16. [CrossRef] [PubMed]

195. Lepak, A.J.; Zhao, M.; Marchillo, K.; VanHecker, J.; Andes, D.R. In Vivo Pharmacodynamics of Omadacycline against Staphylococcus aureus in the Neutropenic Murine Thigh Infection Model. Antimicrob. Agents Chemother. 2019, 63, e00624-19. [CrossRef] [PubMed]

196. Noel, G.J.; Draper, M.P.; Hait, H.; Tanaka, S.K.; Arbeit, R.D. A randomized, evaluator-blind, phase 2 study comparing the safety and efficacy of omadacycline to those of linezolid for treatment of complicated skin and skin structure infections. Antimicrob. Agents Chemother. 2012, 56, 5650-5654. [CrossRef]

197. O’Riordan, W.; Green, S.; Overcash, J.S.; Puljiz, I.; Metallidis, S.; Gardovskis, J.; Garrity-Ryan, L.; Das, A.F.; Tzanis, E.; Eckburg, P.B.; et al. Omadacycline for Acute Bacterial Skin and Skin-Structure Infections. N. Engl. J. Med. 2019, 380, 528-538. [CrossRef] [PubMed]

198. O’Riordan, W.; Cardenas, C.; Shin, E.; Sirbu, A.; Garrity-Ryan, L.; Das, A.F.; Eckburg, P.B.; Manley, A.; Steenbergen, J.N.; Tzanis, E.; et al. Once-daily oral omadacycline versus twice-daily oral linezolid for acute bacterial skin and skin structure infections (OASIS-2): A phase 3, double-blind, multicentre, randomised, controlled, non-inferiority trial. Lancet. Infect. Dis. 2019, 19, 1080-1090. [CrossRef]

199. Stets, R.; Popescu, M.; Gonong, J.R.; Mitha, I.; Nseir, W.; Madej, A.; Kirsch, C.; Das, A.F.; Garrity-Ryan, L.; Steenbergen, J.N.; et al. Omadacycline for Community-Acquired Bacterial Pneumonia. N. Engl. J. Med. 2019, 380, 517-527. [CrossRef] [PubMed]

200. Mogle, B.T.; Steele, J.M.; Thomas, S.J.; Bohan, K.H.; Kufel, W.D. Clinical review of delafloxacin: A novel anionic fluoroquinolone. J. Antimicrob. Chemother. 2018, 73, 1439-1451. [CrossRef]

201. Kocsis, B.; Domokos, J.; Szabo, D. Chemical structure and pharmacokinetics of novel quinolone agents represented by avarofloxacin, delafloxacin, finafloxacin, zabofloxacin and nemonoxacin. Ann. Clin. Microbiol. Antimicrob. 2016, 15, 34. [CrossRef]

202. Jorgensen, S.C.J.; Mercuro, N.J.; Davis, S.L.; Rybak, M.J. Delafloxacin: Place in Therapy and Review of Microbiologic, Clinical and Pharmacologic Properties. Infect. Dis. Ther. 2018, 7, 197-217. [CrossRef]

203. Scott, L.J. Delafloxacin: A Review in Acute Bacterial Skin and Skin Structure Infections. Drugs 2020, 80, 1247-1258. [CrossRef]

204. McCurdy, S.; Lawrence, L.; Quintas, M.; Woosley, L.; Flamm, R.; Tseng, C.; Cammarata, S. In Vitro Activity of Delafloxacin and Microbiological Response against Fluoroquinolone-Susceptible and Nonsusceptible Staphylococcus aureus Isolates from Two Phase 3 Studies of Acute Bacterial Skin and Skin Structure Infections. Antimicrob. Agents Chemother. 2017, 61, e00772-17. [CrossRef]

205. O’Riordan, W.; McManus, A.; Teras, J.; Poromanski, I.; Cruz-Saldariagga, M.; Quintas, M.; Lawrence, L.; Liang, S.; Cammarata, S. A Comparison of the Efficacy and Safety of Intravenous Followed by Oral Delafloxacin With Vancomycin Plus Aztreonam for the Treatment of Acute Bacterial Skin and Skin Structure Infections: A Phase 3, Multinational, Double-Blind, Randomized Study. Clin. Infect. Dis. 2018, 67, 657-666. [CrossRef]

206. McCurdy, S.; Keedy, K.; Lawrence, L.; Nenninger, A.; Sheets, A.; Quintas, M.; Cammarata, S. Efficacy of Delafloxacin versus Moxifloxacin against Bacterial Respiratory Pathogens in Adults with Community-Acquired Bacterial Pneumonia (CABP): Microbiology Results from the Delafloxacin Phase 3 CABP Trial. Antimicrob. Agents Chemother. 2020, 64, e01949-19. [CrossRef]

207. McCurdy, S.; Nenninger, A.; Sheets, A.; Keedy, K.; Lawrence, L.; Quintas, M.; Cammarata, S. Efficacy of delafloxacin versus moxifloxacin against atypical bacterial respiratory pathogens in adults with community-acquired bacterial pneumonia (CABP): Data from the Delafloxacin Phase 3 CABP Trial. Int. J. Infect. Dis. 2020, 97, 374-379. [CrossRef]

208. Hook, E.W., 3rd; Golden, M.R.; Taylor, S.N.; Henry, E.; Tseng, C.; Workowski, K.A.; Swerdlow, J.; Nenninger, A.; Cammarata, S. Efficacy and Safety of Single-Dose Oral Delafloxacin Compared with Intramuscular Ceftriaxone for Uncomplicated Gonorrhea Treatment: An Open-Label, Noninferiority, Phase 3, Multicenter, Randomized Study. Sex. Transm. Dis. 2019, 46, 279-286. [CrossRef]

209. Pullman, J.; Gardovskis, J.; Farley, B.; Sun, E.; Quintas, M.; Lawrence, L.; Ling, R.; Cammarata, S. Efficacy and safety of delafloxacin compared with vancomycin plus aztreonam for acute bacterial skin and skin structure infections: A Phase 3, double-blind, randomized study. J. Antimicrob. Chemother. 2017, 72, 3471-3480. [CrossRef] 
210. O'Riordan, W.; Mehra, P.; Manos, P.; Kingsley, J.; Lawrence, L.; Cammarata, S. A randomized phase 2 study comparing two doses of delafloxacin with tigecycline in adults with complicated skin and skin-structure infections. Int. J. Infect. Dis. IJID Off. Publ. Int. Soc. Infect. Dis. 2015, 30, 67-73. [CrossRef] [PubMed]

211. Kingsley, J.; Mehra, P.; Lawrence, L.E.; Henry, E.; Duffy, E.; Cammarata, S.K.; Pullman, J. A randomized, double-blind, Phase 2 study to evaluate subjective and objective outcomes in patients with acute bacterial skin and skin structure infections treated with delafloxacin, linezolid or vancomycin. J. Antimicrob. Chemother. 2016, 71, 821-829. [CrossRef] [PubMed]

212. Peyclit, L.; Baron, S.A.; Rolain, J.-M. Drug Repurposing to Fight Colistin and Carbapenem-Resistant Bacteria. Front. Cell. Infect. Microbiol. 2019, 9, 193. [CrossRef] [PubMed]

213. Kaul, G.; Shukla, M.; Dasgupta, A.; Chopra, S. Update on drug-repurposing: Is it useful for tackling antimicrobial resistance? Future Microbiol. 2019, 14, 829-831. [CrossRef] [PubMed]

214. Miró-Canturri, A.; Ayerbe-Algaba, R.; Smani, Y. Drug Repurposing for the Treatment of Bacterial and Fungal Infections. Front. Microbiol. 2019, 10, 41. [CrossRef] [PubMed]

215. Hu, Y.; Liu, Y.; Coates, A. Azidothymidine Produces Synergistic Activity in Combination with Colistin against Antibiotic-Resistant Enterobacteriaceae. Antimicrob. Agents Chemother. 2019, 63, e01630-18. [CrossRef] [PubMed]

216. Ng, S.M.S.; Sioson, J.S.P.; Yap, J.M.; Ng, F.M.; Ching, H.S.V.; Teo, J.W.P.; Jureen, R.; Hill, J.; Chia, C.S.B. Repurposing Zidovudine in combination with Tigecycline for treating carbapenem-resistant Enterobacteriaceae infections. Eur. J. Clin. Microbiol. Infect. Dis. Off. Publ. Eur. Soc. Clin. Microbiol. 2018, 37, 141-148. [CrossRef] [PubMed]

217. Carlson-Banning, K.M.; Chou, A.; Liu, Z.; Hamill, R.J.; Song, Y.; Zechiedrich, L. Toward repurposing ciclopirox as an antibiotic against drug-resistant Acinetobacter baumannii, Escherichia coli, and Klebsiella pneumoniae. PLoS ONE 2013, 8, e69646. [CrossRef]

218. Gajdošová, M.; Vetchý, D.; Muselík, J.; Gajdziok, J.; Juřica, J.; Vetchá, M.; Hauptman, K.; Jekl, V. Bilayer mucoadhesive buccal films with prolonged release of ciclopirox olamine for the treatment of oral candidiasis: In vitro development, ex vivo permeation testing, pharmacokinetic and efficacy study in rabbits. Int. J. Pharm. 2021, 592, 120086. [CrossRef]

219. Hijazi, S.; Visaggio, D.; Pirolo, M.; Frangipani, E.; Bernstein, L.; Visca, P. Antimicrobial Activity of Gallium Compounds on ESKAPE Pathogens. Front. Cell. Infect. Microbiol. 2018, 8, 316. [CrossRef]

220. Tran, T.B.; Wang, J.; Doi, Y.; Velkov, T.; Bergen, P.J.; Li, J. Novel Polymyxin Combination with Antineoplastic Mitotane Improved the Bacterial Killing Against Polymyxin-Resistant Multidrug-Resistant Gram-Negative Pathogens. Front. Microbiol. 2018, 9, 721. [CrossRef]

221. Hussein, M.H.; Schneider, E.K.; Elliott, A.G.; Han, M.; Reyes-Ortega, F.; Morris, F.; Blastovich, M.A.T.; Jasim, R.; Currie, B.; Mayo, M.; et al. From Breast Cancer to Antimicrobial: Combating Extremely Resistant Gram-Negative "Superbugs" Using Novel Combinations of Polymyxin B with Selective Estrogen Receptor Modulators. Microb. Drug Resist. 2017, 23, 640-650. [CrossRef]

222. Otto, R.G.; van Gorp, E.; Kloezen, W.; Meletiadis, J.; van den Berg, S.; Mouton, J.W. An alternative strategy for combination therapy: Interactions between polymyxin B and non-antibiotics. Int. J. Antimicrob. Agents 2019, 53, 34-39. [CrossRef]

223. Welton, T. Ionic liquids: A brief history. Biophys. Rev. 2018, 10, 691-706. [CrossRef]

224. Pendleton, J.N.; Gilmore, B.F. The antimicrobial potential of ionic liquids: A source of chemical diversity for infection and biofilm control. Int. J. Antimicrob. Agents 2015, 46, 131-139. [CrossRef]

225. Singh, S.K.; Savoy, A.W. Ionic liquids synthesis and applications: An overview. J. Mol. Liq. 2020, 297, 112038. [CrossRef]

226. Agatemor, C.; Ibsen, K.N.; Tanner, E.E.L.; Mitragotri, S. Ionic liquids for addressing unmet needs in healthcare. Bioeng. Transl. Med. 2018, 3, 7-25. [CrossRef] [PubMed]

227. Kumari, P.; Pillai, V.V.S.; Benedetto, A. Mechanisms of action of ionic liquids on living cells: The state of the art. Biophys. Rev. 2020, 12, 1187-1215. [CrossRef] [PubMed]

228. Łuczak, J.; Jungnickel, C.; Łącka, I.; Stolte, S.; Hupka, J. Antimicrobial and surface activity of 1-alkyl-3-methylimidazolium derivatives. Green Chem. 2010, 12, 593-601. [CrossRef]

229. Miskiewicz, A.; Ceranowicz, P.; Szymczak, M.; Bartuś, K.; Kowalczyk, P. The Use of Liquids Ionic Fluids as Pharmaceutically Active Substances Helpful in Combating Nosocomial Infections Induced by Klebsiella Pneumoniae New Delhi Strain, Acinetobacter Baumannii and Enterococcus Species. Int. J. Mol. Sci. 2018, 19, 2779. [CrossRef] [PubMed]

230. Martini Garcia, I.; Jung Ferreira, C.; de Souza, V.S.; Castelo Branco Leitune, V.; Samuel, S.M.W.; de Souza Balbinot, G.; de Souza da Motta, A.; Visioli, F.; Damiani Scholten, J.; Mezzomo Collares, F. Ionic liquid as antibacterial agent for an experimental orthodontic adhesive. Dent. Mater. 2019, 35, 1155-1165. [CrossRef]

231. Hodyna, D.; Bardeau, J.-F.; Metelytsia, L.; Riabov, S.; Kobrina, L.; Laptiy, S.; Kalashnikova, L.; Parkhomenko, V.; Tarasyuk, O.; Rogalsky, S. Efficient antimicrobial activity and reduced toxicity of 1-dodecyl-3-methylimidazolium tetrafluoroborate ionic liquid / $\beta$-cyclodextrin complex. Chem. Eng. J. 2016, 284, 1136-1145. [CrossRef]

232. Benedetto, A.; Ballone, P. Room-Temperature Ionic Liquids and Biomembranes: Setting the Stage for Applications in Pharmacology, Biomedicine, and Bionanotechnology. Langmuir 2018, 34, 9579-9597. [CrossRef] [PubMed]

233. Jha, G.; Sahu, P.K.; Panda, S.; Singh, D.V.; Patole, S.; Mohapatra, H.; Sarkar, M. Synthesis, Photophysical Studies on Some Anthracene-based Ionic Liquids and their Application as Biofilm Formation Inhibitor. ChemistrySelect 2017, 2, 2426-2432. [CrossRef]

234. Egorova, K.S.; Gordeev, E.G.; Ananikov, V.P. Biological Activity of Ionic Liquids and Their Application in Pharmaceutics and Medicine. Chem. Rev. 2017, 117, 7132-7189. [CrossRef] [PubMed]

235. Guo, J.; Xu, Q.; Zheng, Z.; Zhou, S.; Mao, H.; Wang, B.; Yan, F. Intrinsically Antibacterial Poly(ionic liquid) Membranes: The Synergistic Effect of Anions. ACS Macro Lett. 2015, 4, 1094-1098. [CrossRef] 
236. Ferraz, R.; Silva, D.; Dias, A.R.; Dias, V.; Santos, M.M.; Pinheiro, L.; Prudêncio, C.; Noronha, J.P.; Petrovski, Ž.; Branco, L.C. Synthesis and Antibacterial Activity of Ionic Liquids and Organic Salts Based on Penicillin G and Amoxicillin hydrolysate Derivatives against Resistant Bacteria. Pharmaceutics 2020, 12, 221. [CrossRef]

237. Cole, M.R.; Hobden, J.A.; Warner, I.M. Recycling antibiotics into GUMBOS: A new combination strategy to combat multi-drugresistant bacteria. Molecules 2015, 20,6466-6487. [CrossRef]

238. Dang, T.; Nizamov, I.S.; Salikhov, R.Z.; Sabirzyanova, L.R.; Vorobev, V.V.; Burganova, T.I.; Shaidoullina, M.M.; Batyeva, E.S.; Cherkasov, R.A.; Abdullin, T.I. Synthesis and characterization of pyridoxine, nicotine and nicotinamide salts of dithiophosphoric acids as antibacterial agents against resistant wound infection. Bioorg. Med. Chem. 2019, 27, 100-109. [CrossRef] [PubMed]

239. Ferraz, R.; Teixeira, V.; Rodrigues, D.; Fernandes, R.; Noronha, J.P.; Branco, L.C.; Petrovski, Ž.; Prudêncio, C. Antibacterial activity of Ionic Liquids based on ampicillin against resistant bacteria. RSC Adv. 2013, 4, 4301-4307. [CrossRef]

240. Prudêncio, C.; Vieira, M.; Van der Auweraer, S.; Ferraz, R. Recycling Old Antibiotics with Ionic Liquids. Antibiotics 2020, 9 , 578. [CrossRef] [PubMed]

241. Liu, S.; Gonzalez, M.; Kong, C.; Weir, S.; Socha, A.M. Synthesis, antibiotic structure-activity relationships, and cellulose dissolution studies of new room-temperature ionic liquids derived from lignin. Biotechnol. Biofuels 2021, 14, 47. [CrossRef] [PubMed]

242. Smith, C.A.; Cataldo, V.A.; Dimke, T.; Stephan, I.; Guterman, R. Antibacterial and Degradable Thioimidazolium Poly(ionic liquid). ACS Sustain. Chem. Eng. 2020, 8, 8419-8424. [CrossRef]

243. Zheng, Z.; Xu, Q.; Guo, J.; Qin, J.; Mao, H.; Wang, B.; Yan, F. Structure-Antibacterial Activity Relationships of Imidazolium-Type Ionic Liquid Monomers, Poly(ionic liquids) and Poly(ionic liquid) Membranes: Effect of Alkyl Chain Length and Cations. ACS Appl. Mater. Interfaces 2016, 8, 12684-12692. [CrossRef] [PubMed]

244. Deng, X.; Cao, S.; Horn, A.L. Emerging Applications of Machine Learning in Food Safety. Annu. Rev. Food Sci. Technol. 2021, 12, 513-538. [CrossRef]

245. Grear, T.; Avery, C.; Patterson, J.; Jacobs, D.J. Molecular function recognition by supervised projection pursuit machine learning. Sci. Rep. 2021, 11, 4247. [CrossRef] [PubMed]

246. Stokes, J.M.; Yang, K.; Swanson, K.; Jin, W.; Cubillos-Ruiz, A.; Donghia, N.M.; MacNair, C.R.; French, S.; Carfrae, L.A.; Bloom-Ackermann, Z.; et al. A Deep Learning Approach to Antibiotic Discovery. Cell 2020, 180, 688-702. [CrossRef] [PubMed]

247. Smith, N.M.; Lenhard, J.R.; Boissonneault, K.R.; Landersdorfer, C.B.; Bulitta, J.B.; Holden, P.N.; Forrest, A.; Nation, R.L.; Li, J.; Tsuji, B.T. Using machine learning to optimize antibiotic combinations: Dosing strategies for meropenem and polymyxin B against carbapenem-resistant Acinetobacter baumannii. Clin. Microbiol. Infect. 2020, 26, 1207-1213. [CrossRef]

248. Chapman, J.; Orrell-Trigg, R.; Kwoon, K.Y.; Truong, V.K.; Cozzolino, D. A high-throughput and machine learning resistance monitoring system to determine the point of resistance for Escherichia coli with tetracycline: Combining UV-visible spectrophotometry with principal component analysis. Biotechnol. Bioeng. 2021, 118, 1511-1519. [CrossRef]

249. Parvaiz, N.; Ahmad, F.; Yu, W.; MacKerell, A.D.J.; Azam, S.S. Discovery of beta-lactamase CMY-10 inhibitors for combination therapy against multi-drug resistant Enterobacteriaceae. PLoS ONE 2021, 16, e0244967. [CrossRef] [PubMed]

250. Mienda, B.S.; Dräger, A. Genome-Scale Metabolic Modeling of Escherichia coli and Its Chassis Design for Synthetic Biology Applications. Methods Mol. Biol. 2021, 2189, 217-229. [CrossRef]

251. Torres, M.D.T.; Cao, J.; Franco, O.L.; Lu, T.K.; de la Fuente-Nunez, C. Synthetic Biology and Computer-Based Frameworks for Antimicrobial Peptide Discovery. ACS Nano 2021, 15, 2143-2164. [CrossRef]

252. Li, Q.; Pellegrino, J.; Lee, D.J.; Tran, A.A.; Chaires, H.A.; Wang, R.; Park, J.E.; Ji, K.; Chow, D.; Zhang, N.; et al. Synthetic group A streptogramin antibiotics that overcome Vat resistance. Nature 2020, 586, 145-150. [CrossRef]

253. Gerstmans, H.; Criel, B.; Briers, Y. Synthetic biology of modular endolysins. Biotechnol. Adv. 2018, 36, 624-640. [CrossRef]

254. Doi, Y.; Paterson, D.L. Carbapenemase-producing Enterobacteriaceae. Semin. Respir. Crit. Care Med. 2015, 36, 74-84. [CrossRef] [PubMed]

255. Fernando, S.A.; Gray, T.J.; Gottlieb, T. Healthcare-acquired infections: Prevention strategies. Intern. Med. J. 2017, 47, 1341-1351. [CrossRef] [PubMed]

256. Chang, L.W.K.; Buising, K.L.; Jeremiah, C.J.; Cronin, K.; Poy Lorenzo, Y.S.; Howden, B.P.; Kwong, J.; Cocks, J.; Blood, A.; Greenough, J.; et al. Managing a nosocomial outbreak of carbapenem-resistant Klebsiella pneumoniae: An early Australian hospital experience. Intern. Med. J. 2015, 45, 1037-1043. [CrossRef] [PubMed]

257. World Health Organization. WHO Guidelines on Hand Hygiene in Health Care: First Global Patient Safety Challenge Clean Care Is Safer Care; WHO: Geneva, Switzerland, 2009; ISBN 978-92-4-159790-6.

258. Pittet, D.; Allegranzi, B.; Sax, H.; Dharan, S.; Pessoa-Silva, C.L.; Donaldson, L.; Boyce, J.M. Evidence-based model for hand transmission during patient care and the role of improved practices. Lancet Infect. Dis. 2006, 6, 641-652. [CrossRef]

259. Allegranzi, B.; Pittet, D. Role of hand hygiene in healthcare-associated infection prevention. J. Hosp. Infect. 2009, 73, 305-315. [CrossRef] [PubMed]

260. Sax, H.; Allegranzi, B.; Uçkay, I.; Larson, E.; Boyce, J.; Pittet, D. “My five moments for hand hygiene”: A user-centred design approach to understand, train, monitor and report hand hygiene. J. Hosp. Infect. 2007, 67, 9-21. [CrossRef]

261. Barlam, T.F.; Cosgrove, S.E.; Abbo, L.M.; MacDougall, C.; Schuetz, A.N.; Septimus, E.J.; Srinivasan, A.; Dellit, T.H.; Falck-Ytter, Y.T.; Fishman, N.O.; et al. Implementing an Antibiotic Stewardship Program: Guidelines by the Infectious Diseases Society of America and the Society for Healthcare Epidemiology of America. Clin. Infect. Dis. 2016, 62, e51-e77. [CrossRef]

262. Moehring, R.W.; Anderson, D.J. Antimicrobial stewardship as part of the infection prevention effort. Curr. Infect. Dis. Rep. 2012, 14, 592-600. [CrossRef] 
263. Suay-García, B.; Pérez-Gracia, M.T. Present and Future of Carbapenem-resistant Enterobacteriaceae (CRE) Infections. Antibiotics 2019, 8, 122. [CrossRef]

264. Kim, H.-R.; Eom, Y.-B. Synergistic Activity of Equol and Meropenem against Carbapenem-Resistant Escherichia coli. Antibiotics 2021, 10, 161. [CrossRef]

265. Noval, M.; Banoub, M.; Claeys, K.C.; Heil, E. The Battle Is on: New Beta-Lactams for the Treatment of Multidrug-Resistant Gram-Negative Organisms. Curr. Infect. Dis. Rep. 2020, 22, 1. [CrossRef] [PubMed]

266. Campanella, T.A.; Gallagher, J.C. A Clinical Review and Critical Evaluation of Imipenem-Relebactam: Evidence to Date. Infect. Drug Resist. 2020, 13, 4297-4308. [CrossRef] [PubMed]

267. Endimiani, A.; Hujer, K.M.; Hujer, A.M.; Armstrong, E.S.; Choudhary, Y.; Aggen, J.B.; Bonomo, R.A. ACHN-490, a neoglycoside with potent in vitro activity against multidrug-resistant Klebsiella pneumoniae isolates. Antimicrob. Agents Chemother. 2009, 53, 4504-4507. [CrossRef] [PubMed]

268. Papp-Wallace, K.M.; Nguyen, N.Q.; Jacobs, M.R.; Bethel, C.R.; Barnes, M.D.; Kumar, V.; Bajaksouzian, S.; Rudin, S.D.; Rather, P.N.; Bhavsar, S.; et al. Strategic Approaches to Overcome Resistance against Gram-Negative Pathogens Using $\beta$-Lactamase Inhibitors and $\beta$-Lactam Enhancers: Activity of Three Novel Diazabicyclooctanes WCK 5153, Zidebactam (WCK 5107), and WCK 4234. J. Med. Chem. 2018, 61, 4067-4086. [CrossRef] [PubMed] 